\title{
Volatile and Organic Compositions of Sedimentary Rocks in Yellowknife Bay, Gale crater, Mars
}

D. W. Ming ${ }^{1, *}$, P. D. Archer, Jr. ${ }^{2}$, D. P. Glavin ${ }^{3}$, J. L. Eigenbrode ${ }^{3}$, H. B. Franz ${ }^{3,4}$, B. Sutter $^{2}$, A. E. Brunner ${ }^{3,5}$, J. C. Stern ${ }^{3}$, C. Freissinet ${ }^{3,6}$, A. C. McAdam ${ }^{3}$, P. R. Mahaffy ${ }^{3}$, M. Cabane ${ }^{7}$, P. Coll ${ }^{8}$, J. L. Campbell ${ }^{9}$, S. K. Atreya ${ }^{10}$, P. B. Niles ${ }^{1}$, J. F. Bell III ${ }^{11}$, D. L. Bish $^{12}$, W. B. Brinckerhoff ${ }^{3}$, A. Buch ${ }^{13}$, P. G. Conrad ${ }^{3}$, D. J. Des Marais ${ }^{14}$, B. L. Ehlmann ${ }^{15,16}$, A. G. Fairén ${ }^{17}$, K. Farley ${ }^{15}$, G. J. Flesch ${ }^{16}$, P. Francois ${ }^{8}$, R. Gellert ${ }^{9}$, J. A. Grant $^{18}$, J. P. Grotzinger ${ }^{15}$, S. Gupta ${ }^{19}$, K. E. Herkenhoff ${ }^{20}$, J. A. Hurowitz ${ }^{21}$, L. A. Leshin $^{22}$, K. W. Lewis ${ }^{23}$, S. M. McLennan ${ }^{21}$, K. E. Miller ${ }^{24}$, J. Moersch ${ }^{25}$, R. V. Morris ${ }^{1}$, R. Navarro-González ${ }^{26}$, A. A. Pavlov ${ }^{3}$, G. M. Perrett ${ }^{9}$, I. Pradler ${ }^{9}$, S. W. Squyres ${ }^{17}$, R. E. Summons $^{24}$, A. Steele ${ }^{27}$, E. M. Stolper ${ }^{15}$, D. Y. Sumner ${ }^{28}$, C. Szopa ${ }^{8}$, S. Teinturier ${ }^{8}$, M. G.

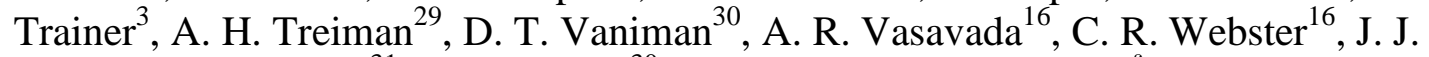
Wray $^{31}$, R. A. Yingst ${ }^{30}$ and the MSL Science Team ${ }^{\S}$.

\section{Affiliations:}

${ }^{1}$ Astromaterials Research and Exploration Science Directorate, NASA Johnson Space Center, Houston, TX 77058, USA.

${ }^{2}$ Jacobs, Houston, TX 77058, USA.

${ }^{3}$ Planetary Environments Laboratory, NASA Goddard Space Flight Center, Greenbelt MD 20771, USA.

${ }^{4}$ Center for Research and Exploration in Space Science and Technology, University of Maryland Baltimore County, Baltimore, MD 21250, USA.

${ }^{5}$ Center for Research and Exploration in Space Science and Technology, Department of Astronomy, University of Maryland, College Park, MD 20742, USA.

${ }^{6}$ NASA Postdoctoral Program, NASA Goddard Space Flight Center, Greenbelt MD 20771, USA.

${ }^{7}$ LATMOS, UPMC Univ. Paris 06, Université Versailles St-Quentin, UMR CNRS 8970, 75005 Paris, France.

${ }^{8}$ LISA, Univ. Paris-Est Créteil, Univ. Paris Diderot \& CNRS, 94000 Créteil, France.

${ }^{9}$ Department of Physics, University of Guelph, Guelph, Ontario, Canada N1G2W1.

${ }^{10}$ Department of Atmospheric, Oceanic and Space Sciences, University of Michigan, Ann Arbor, MI 48109-2143, USA.

${ }^{11}$ School of Earth and Space Exploration, Arizona State University, Tempe, AZ 85287, USA.

${ }^{12}$ Department of Geological Sciences, Indiana University, Bloomington, IN 47405, USA.

${ }^{13}$ LGPM, Ecole Centrale Paris, 92295 Chatenay-Malabry, France. 
${ }^{14}$ Department of Space Sciences, NASA Ames Research Center, Moffett Field, CA 94035, USA.

${ }^{15}$ Division of Geologic and Planetary Sciences, California Institute of Technology, Pasadena, CA, 91125, USA.

${ }^{16}$ Jet Propulsion Laboratory, California Institute of Technology, Pasadena, CA 91109 , USA.

${ }^{17}$ Department of Astronomy, Cornell University, Ithaca, NY 14853, USA.

${ }^{18}$ Center for Earth and Planetary Studies, National Air and Space Museum, Smithsonian Institution, Washington, DC 20560, USA

${ }^{19}$ Department of Earth Science and Engineering, Imperial College London, London, SW7 2AZ, UK.

${ }^{20}$ U.S. Geological Survey, Flagstaff, AZ 86001, USA.

${ }^{21}$ Department of Geosciences, State University of New York State at Stony Brook, NY 11794-2100, USA.

${ }^{22}$ Department of Earth \& Environmental Science and School of Science, Rensselaer Polytechnic Institute, Troy, NY 12180, USA.

${ }^{23}$ Princeton University, Princeton, NJ 08544, USA.

${ }^{24}$ Department of Earth, Atmospheric and Planetary Sciences, Massachusetts Institute of Technology, Cambridge, MA 02139, USA.

${ }^{25}$ Department of Earth and Planetary Sciences, University of Tennessee, Knoxville, TN 37996, USA.

${ }^{26}$ Instituto de Ciencias Nucleares, Universidad Nacional Autónoma de México, Ciudad Universitaria, México D.F. 04510, Mexico.

${ }^{27}$ Geophysical Laboratory, Carnegie Institution of Washington, Washington DC 20015, USA.

${ }^{28}$ Department of Earth and Planetary Sciences, University of California, Davis, CA 95616, USA.

${ }^{29}$ Lunar and Planetary Institute, Houston, TX 77058, USA.

${ }^{30}$ Planetary Science Institute, Tucson, AZ 85719, USA.

${ }^{31}$ School of Earth and Atmospheric Sciences, Georgia Institute of Technology, Atlanta, GA 30332, USA.

*Corresponding to: douglas.w.ming@nasa.gov

${ }^{\S}$ MSL Science Team authors and affiliations are listed in the supplementary materials.

Abstract: $\mathrm{H}_{2} \mathrm{O}, \mathrm{CO}_{2}, \mathrm{SO}_{2}, \mathrm{O}_{2}, \mathrm{H}_{2}, \mathrm{H}_{2} \mathrm{~S}, \mathrm{HCl}$, chlorinated hydrocarbons, $\mathrm{NO}$ and other trace gases were evolved during pyrolysis of two mudstone samples acquired by the Curiosity rover at Yellowknife Bay within Gale crater, Mars. $\mathrm{H}_{2} \mathrm{O} / \mathrm{OH}$-bearing phases included 2:1 phyllosilicate(s), bassanite, akaganeite, and amorphous materials. Thermal 
decomposition of carbonates and combustion of organic materials are candidate sources for the $\mathrm{CO}_{2}$. Concurrent evolution of $\mathrm{O}_{2}$ and chlorinated hydrocarbons suggest the presence of oxychlorine phase(s). Sulfides are likely sources for S-bearing species. Higher abundances of chlorinated hydrocarbons in the mudstone compared with Rocknest windblown materials previously analyzed by Curiosity suggest that indigenous martian or meteoritic organic $\mathrm{C}$ sources may be preserved in the mudstone; however, the $\mathrm{C}$ source for the chlorinated hydrocarbons is not definitively of martian origin.

Introduction: Curiosity landed in Gale crater on August 6, 2012 (UTC) with a goal to explore and quantitatively assess a site on Mars' surface as a potential habitat for past or present life. A topographic low informally named Yellowknife Bay located about $0.5 \mathrm{~km}$ northeast of the landing site was chosen as the first major exploration target because strata exposed were inferred to be fluvio-lacustrine deposits (1). Fluvio-lacustrine depositional systems are thought to preserve measurable evidence of paleo-habitability (2), e.g., factors such as mineral associations, elemental inventory, redox state, and character of light elements and compounds.

Curiosity entered Yellowknife Bay on Sol 125 (December 12, 2012) and began a drilling campaign to obtain powder samples from a mudstone located near the base of an exposed stratal succession $(3,4)$. Two drill samples informally named John Klein (drilled on sol 183) and Cumberland (drilled on sol 279) were extracted for delivery to the Sample Analysis at Mars (SAM) (5) and Chemistry and Mineralogy (CheMin) (6) instruments. The samples were obtained from the lowermost stratigraphic unit in the Yellowknife Bay formation, informally named the Sheepbed member (1). The Sheepbed member and an overlying medium to coarse-grained sandstone, named the Gillespie Lake member, appear to have a complex post-depositional aqueous history. Apparent low matrix permeability in these units suggests that they were lithified during an early diagenetic event followed by at least one additional aqueous episode when Ca-sulfate minerals precipitated in a network of intersecting fractures (7). Millimeter-sized nodules and hollow nodules in the Sheepbed member are interpreted, respectively, to be concretions and void spaces possibly formed as trapped gas bubbles during early diagenesis and lithification (1). The geology, stratigraphy, and diagenetic history of Yellowknife Bay are described in detail in companion papers $(1,7,8)$.

The John Klein (JK) and Cumberland (CB) targets were drilled about 3 meters apart in the Sheepbed mudstone and within $\approx 10 \mathrm{~cm}$ of the same stratigraphic position. The JK drill hole intersected thin Ca-sulfate-rich veins. The CB sample was collected from an area rich in nodules and poor in $\mathrm{Ca}$-sulfate-rich veins, to aid in mineralogical and geochemical characterization of the nodules. Powders extracted from both holes were gray in color suggesting a relatively unoxidized material $(1,8)$, in contrast to the redcolored, oxidized materials observed earlier by Curiosity at the Rocknest aeolian deposit $(9,10)$ and other surface soils $(11)$ encountered by previous missions (12). Additional details on the drill holes are described in (1) and (8), including maps of light-toned fractures in the drill hole walls (8).

Here we describe the volatile and organic $\mathrm{C}$ content of the Sheepbed mudstone and evaluate its potential for preservation of organic C. Volatile-bearing phases 
(including possible organic material) in Sheepbed are indicators of its past environmental and geochemical conditions and can shed light on whether the environment recorded in this mudstone once was habitable, i.e., met the requirements for microbial life as known on Earth (13). The volatile and organic compositions of JK and CB materials were characterized by the SAM instrument's evolved gas analysis (EGA), gas chromatography mass spectrometry (GCMS), and tunable laser spectroscopy (TLS) experiments (14). Four JK subsamples (JK-1, JK-2, JK-3, and JK-4) and four CB subsamples (CB-1, CB-2, CB-3, and CB-5) of the $<150 \mu \mathrm{m}$ size fraction of drill fines were delivered to SAM for EGA and GCMS analyses (15).

Evolved $\mathrm{H}_{2} \mathrm{O}$. The most abundant gas evolved from JK and $\mathrm{CB}$ materials was $\mathrm{H}_{2} \mathrm{O}$. $\mathrm{H}_{2} \mathrm{O}$ abundances released from $\mathrm{JK}\left(1.8-2.4\right.$ wt. $\left.\% \mathrm{H}_{2} \mathrm{O}\right)$ and $\mathrm{CB}\left(1.7-2.5\right.$ wt. $\% \mathrm{H}_{2} \mathrm{O}$; Table 1$)$ were similar to Rocknest $\left(1.6-2.4\right.$ wt. $\left.\% \mathrm{H}_{2} \mathrm{O}\right)(10)$. Other major evolved gases, in descending order of abundance, were $\mathrm{H}_{2}, \mathrm{CO}_{2}, \mathrm{SO}_{2}$, and $\mathrm{O}_{2}$ from $\mathrm{JK}$ and $\mathrm{H}_{2}, \mathrm{O}_{2}, \mathrm{CO}_{2}$, and $\mathrm{SO}_{2}$ from CB (Table 1, Figs. 1 and 2).

An independent estimate of the volatile inventory of JK and CB can be obtained from measurements made by the Alpha Particle X-ray Spectrometer (APXS) (16). The measurement calculates the bulk concentration of the aggregate of excess light elements (including $\mathrm{H}_{2} \mathrm{O}, \mathrm{CO}_{2}, \mathrm{C}, \mathrm{F}, \mathrm{B}_{2} \mathrm{O}_{3}$ and $\mathrm{Li}_{2} \mathrm{O}$ ) using the relative intensities of Compton- and Rayleigh-scattering peaks $(17,14)$. Estimates of the average excess light-element concentrations for the JK drill tailings (APXS measurement on Sol 230) and the CB drill tailings (Sol 287) were $4.3( \pm 5.5)$ and $6.9( \pm 6.2)$ wt. \%, respectively. The two methods for determining volatile abundances in the mudstone are consistent within uncertainties.

The JK and CB samples showed similar releases of $\mathrm{H}_{2} \mathrm{O}$ in EGA experiments with a continuous temperature ramp (Figs. 1a, 2a) (18,19). Evolved $\mathrm{H}_{2} \mathrm{O}$ from JK (JK-4) resulted in two major $\mathrm{H}_{2} \mathrm{O}$ releases, with very broad peaks at about 160 and $725^{\circ} \mathrm{C}$ (Fig. 1a). Cumberland samples exhibited similar behavior (Fig. 2 a). The majority $(\sim 70 \%)$ of $\mathrm{H}_{2} \mathrm{O}$ was driven off in the lower temperature peak.

CheMin results constrain the potential phases releasing $\mathrm{H}_{2} \mathrm{O}$ in the lower peak in JK and CB samples. CheMin detected basaltic silicate minerals (feldspar, pyroxene, olivine), magnetite (maghemite), anhydrite, bassanite, akaganeite, sulfides and approximately $30 \mathrm{wt}$. \% x-ray amorphous components in addition to a 2:1 trioctahedral phyllosilicate in JK and $\mathrm{CB}(8)$. Therefore, candidates for the lower temperature water release are $\mathrm{H}_{2} \mathrm{O}$ adsorbed on grain surfaces, interlayer $\mathrm{H}_{2} \mathrm{O}$ associated with exchangeable cations in 2:1 phyllosilicates (e.g., smectite), structural $\mathrm{H}_{2} \mathrm{O}$ (e.g., bassanite), structural $\mathrm{OH}$ (e.g., Fe-oxyhydroxides such as akaganeite), and occluded $\mathrm{H}_{2} \mathrm{O}$ in glass or minerals. Adsorbed $\mathrm{H}_{2} \mathrm{O}$ and interlayer $\mathrm{H}_{2} \mathrm{O}$ in $2: 1$ phyllosilicates will generally release water below $300{ }^{\circ} \mathrm{C}$. Bassanite $\left(\mathrm{CaSO}_{4} \cdot 1 / 2 \mathrm{H}_{2} \mathrm{O}\right)$ dehydrates at $\sim 150{ }^{\circ} \mathrm{C}$. Akaganeite $(\mathrm{FeO}(\mathrm{OH}, \mathrm{Cl}))$ undergoes dehydroxylation at $\sim 250{ }^{\circ} \mathrm{C}$ (Fig. S2). $\mathrm{H}_{2} \mathrm{O}$ incorporated into the amorphous components (e.g., nanophase Fe-oxides, allophane/hisingerite) may also evolve below $450{ }^{\circ} \mathrm{C}$. Water as liquid or vapor inclusions in glass or minerals would be released over a wide range of temperatures. Additional sources of evolved $\mathrm{H}_{2} \mathrm{O}$ at low temperatures not constrained by CheMin include structural $\mathrm{H}_{2} \mathrm{O}$ in oxychlorine compounds (e.g., hydrated perchlorates), structural $\mathrm{OH}$ in organics, and $\mathrm{H}_{2} \mathrm{O}$ formed 
during organic reactions in the SAM pyrolysis oven. Organic matter can release $\mathrm{H}_{2} \mathrm{O}$ over a wide range of temperatures from structural $\mathrm{O}$ and $\mathrm{H}$ as a consequence of reactions that take place in the SAM oven.

The high-temperature $\mathrm{H}_{2} \mathrm{O}$ release between $450-835{ }^{\circ} \mathrm{C}$ is consistent with the dehydroxylation of the octahedral layer of a 2:1 phyllosilicate (e.g., smectite), although other phases that contain $\mathrm{OH}$ in octahedral layers may also evolve $\mathrm{H}_{2} \mathrm{O}$ in this temperature region. The basal (001) spacing of the JK phyllosilicate measured by CheMin was mostly collapsed to around $10 \AA$ suggesting a $2: 1$ phyllosilicate with little interlayer $\mathrm{H}_{2} \mathrm{O}(8)$. The 2:1 phyllosilicate in the CB sample was expanded, with a basal (001) spacing of $\sim 13-14 \AA$, consistent with several possible interpretations; the CB phyllosilicate could be smectite with an interlayer partially occupied by metal-hydroxyl groups or smectite with high hydration-energy cations (e.g., $\mathrm{Mg}^{2+}$ ) facilitating retention of $\mathrm{H}_{2} \mathrm{O}$ (8). The high-temperature $\mathrm{H}_{2} \mathrm{O}$ releases at $750{ }^{\circ} \mathrm{C}$ can be ascribed to dehydroxylation of $\mathrm{Mg}$ - and Al-enriched octahedral sheets in 2:1 phyllosilicates (Fig. 3a). The most likely candidate for the high-temperature $\mathrm{H}_{2} \mathrm{O}$ release (i.e., $\sim 750^{\circ} \mathrm{C}$ ) in Sheepbed material is saponite or Fe-saponite based upon CheMin measurement of the $02 \boldsymbol{\ell}$ diffraction band (4.58 $\AA$ ) as consistent with a trioctahedral $2: 1$ phyllosilicate $(8)$ and the water release peak temperature (Fig. 3a). If all of the $\mathrm{H}_{2} \mathrm{O}$ released between $450-835^{\circ} \mathrm{C}$ during SAM pyrolysis runs resulted from dehydroxylation of 2:1 phyllosilicates, the proportions of 2:1 phyllosilicate present in the JK and CB samples are $17( \pm 12)$ wt. \% and $16( \pm 11)$ wt. \%, respectively. These values are consistent with the independent estimates from CheMin XRD semi-quantitative data, which give $22( \pm 11)$ and $18( \pm 9)$ wt. $\%$ for 2:1 phyllosilicate in JK and CB, respectively (8).

High-temperature release of $\mathrm{H}_{2}$ occurs over roughly the same temperature regions as the high-temperature releases of $\mathrm{H}_{2} \mathrm{O}$ and $\mathrm{H}_{2} \mathrm{~S}$ (Figs. 1 \& 2). The origin of the high temperature evolved $\mathrm{H}_{2}$ is unknown but is likely associated with the dehydroxylation of the most thermally stable $\mathrm{OH}$ groups in the 2:1 phyllosilicates.

Evolved $\mathrm{O}_{2}$. The $\mathrm{JK}$ and $\mathrm{CB}$ samples have distinctly different $\mathrm{O}_{2}$ releases (Figs. 1a and 2a; Table 1). The onset of $\mathrm{O}_{2}$ evolution from JK $\left(\sim 150{ }^{\circ} \mathrm{C}\right)$ was lower than for $\mathrm{CB}(\sim 230$ $\left.{ }^{\circ} \mathrm{C}\right) . \mathrm{O}_{2}$ abundances released from $\mathrm{CB}\left(0.3-1.3\right.$ wt. $\left.\% \mathrm{Cl}_{2} \mathrm{O}_{7}\right)$ were nearly 8 times greater than JK (0.07-0.24 wt. \% $\left.\mathrm{Cl}_{2} \mathrm{O}_{7}\right)$; Rocknest $\mathrm{O}_{2}$ abundances $\left(0.4\right.$ wt. $\% \mathrm{Cl}_{2} \mathrm{O}_{7}$ ) were about 4 times greater than JK (Table 1). By comparison, the perchlorate anion $\left(\mathrm{ClO}_{4}{ }^{-}\right)$was present in soil at the Phoenix landing site at the $0.4-0.6$ wt \% level (20). The JK-4 sample had two distinct peaks, suggesting different or additional $\mathrm{O}_{2}$-evolving phases in the JK sample or consumption of $\mathrm{O}_{2}$ during combustion of organic materials (see below) or thermal oxidation of ferrous-containing phases (e.g., magnetite to maghemite transition). $\mathrm{O}_{2}$ evolution in the Rocknest aeolian material occurred at a higher temperature (onset $\sim 300{ }^{\circ} \mathrm{C}$ with a peak temperature $\sim 400{ }^{\circ} \mathrm{C}$ ) than $\mathrm{JK}$ and $\mathrm{CB}(10,21)$.

Evolved $\mathrm{O}_{2}$ from $\mathrm{JK}$ and $\mathrm{CB}$ is inferred to result from decomposition of perchlorate or chlorate salts, based on analogy with other analyses on Mars, bulk compositions of the JK and $\mathrm{CB}$ samples, on the timing of chlorinated hydrocarbon and $\mathrm{HCl}$ releases, and on laboratory experiments with perchlorate salts. Perchlorate was definitively identified in soil at the Mars Phoenix landing site (20), and $\mathrm{O}_{2}$ release from 
the Rocknest aeolian material is roughly consistent with decomposition of Ca-perchlorate (10,21). The CB sample contains three times the $\mathrm{Cl}$ of the $\mathrm{JK}$ sample as measured by APXS (1.41 wt. \% vs. 0.4 wt. \% for CB and JK, respectively) (7), and the abundance of $\mathrm{O}_{2}$ released from CB (splits CB-2 \& CB-3) is nearly 8 times greater than from JK (Table 1), suggesting that the substance responsible for the release of $\mathrm{O}_{2}$ from $\mathrm{CB}$ was a perchlorate or chlorate. Similarly, $\mathrm{HCl}$ and chlorinated hydrocarbons (chloromethane and dichloromethane) were released in conjunction with $\mathrm{O}_{2}$ (Figs. 1 \& 2, see below), suggesting that $\mathrm{Cl}$ and $\mathrm{O}$ were hosted by the same compound in $\mathrm{CB}$ and $\mathrm{JK}$.

The coincident release of $\mathrm{HCl}$ with $\mathrm{O}_{2}$ in $\mathrm{CB}$ is consistent with several types of perchlorate salt (Fig. 2). $\mathrm{HCl}$ is evolved during thermal decomposition of $\mathrm{Mg}$ - and $\mathrm{Fe}$ perchlorate, caused by reaction between $\mathrm{Cl}_{2}$ gas and water vapor (22-24). Thermal decomposition of $\mathrm{Ca}$-perchlorate alone does not yield substantial $\mathrm{HCl}$ at temperatures $<450{ }^{\circ} \mathrm{C}(22,25)$. However, thermal decomposition of Ca-perchlorate in the presence of a Fe-bearing mineral such as pyrrhotite can also yield simultaneous releases of $\mathrm{O}_{2}$ and $\mathrm{HCl}$ (Fig. 3b).

The $\mathrm{O}_{2}$-release profiles and temperatures for JK and CB do not match exactly those of common perchlorate salts. Although the best matches are with Fe-perchlorates (Fig. 3c) the presence of Fe-oxides/oxyhydroxides may lower the decomposition temperature of perchlorate salts (26). Chlorate salts may also be stable on the martian surface (27), and mixtures of K-chlorate and hematite can decompose at temperatures consistent with $\mathrm{O}_{2}$-release temperatures observed in JK and $\mathrm{CB}$ (26). Other possible sources of the low temperature $\mathrm{O}_{2}$ release, e.g., peroxides, and superoxide radicals, cannot be ruled out (28-30).

Evolved $\mathrm{CO}_{2}$. The $\mathrm{CO}_{2}$ releases for the $\mathrm{JK}$ and $\mathrm{CB}$ samples peaked at temperatures below $300{ }^{\circ} \mathrm{C}$ (Figs. 1a and 2a), distinct from the $\mathrm{CO}_{2}$ release between $400{ }^{\circ} \mathrm{C}$ and $512{ }^{\circ} \mathrm{C}$ from the Rocknest aeolian materials (10). The $\mathrm{CO}_{2}$ releases in the Rocknest samples were interpreted to derive largely from carbonates (10), and the $\mathrm{CO}_{2}$ release shoulder around $400-450{ }^{\circ} \mathrm{C}$ in the JK samples could also derive from carbonate minerals, specifically fine-grained $\mathrm{Fe} / \mathrm{Mg}$-carbonate $(24,10,31)$. The $400-450{ }^{\circ} \mathrm{C}$ release shoulder is absent from the $\mathrm{CB}$ samples. Another possible $\mathrm{CO}_{2}$ source, given the inferred presence of akaganeite and substantial proportions of perchlorate or chlorate phases in the samples, is that $\mathrm{HCl}$ evolved at lower temperatures, and then reacted with carbonate minerals (23). The onset of evolved $\mathrm{HCl}$ is nearly simultaneous with $\mathrm{CO}_{2}$ releases in $\mathrm{JK}$ and $\mathrm{CB}$ (Figs. 1 $\& 2$ ), suggesting that low-temperature acid dissolution and subsequent thermal decomposition of carbonates may be responsible for some of the evolved $\mathrm{CO}_{2}$ (Fig. S2). Total $\mathrm{CO}_{2}$ evolved is equivalent to $<1 \mathrm{wt}$. \% carbonate and, if present, carbonates are at abundance below the detection limit by CheMin. Adsorbed $\mathrm{CO}_{2}$ is an unlikely candidate for the $\mathrm{CO}_{2}$ peak near $300{ }^{\circ} \mathrm{C}$ because the majority of adsorbed $\mathrm{CO}_{2}$ is expected to be desorbed from smectite and palagonite-like material surfaces at temperatures $<200{ }^{\circ} \mathrm{C}$ (32). The low-temperature shoulder around 100-200 ${ }^{\circ} \mathrm{C}$ in $\mathrm{JK}$ materials could reflect adsorbed $\mathrm{CO}_{2}$, although it was not seen in $\mathrm{CB}$ materials.

Although there are several possible $\mathrm{CO}_{2}$ sources in $\mathrm{JK}$ and $\mathrm{CB}$ materials, the simultaneous evolution of $\mathrm{CO}_{2}$ and $\mathrm{O}_{2}$ in conjunction with a possible $\mathrm{O}_{2}$ inversion (i.e., 
$\mathrm{O}_{2}$ consumption) in $\mathrm{JK}-4$ and the similar $\mathrm{CO}_{2}$ and $\mathrm{O}_{2}$ releases in $\mathrm{CB}$ samples suggest combustion of $\mathrm{C}$ compounds. It is nearly certain that at least some of the $\mathrm{CO}_{2}$ produced is derived from the combustion of vapor from $N$-methyl- $N$-(tert-butyldimethylsilyl) trifluoroacetamide (MTBSTFA, a derivatization agent carried in SAM) and its reaction products that were identified by the EGA and GCMS experiments and adsorbed onto the samples and sample cups inside SAM during sample transfer in Curiosity's sample acquisition and processing system $(33,10,21)$. The background-derived $\mathrm{C}$ detected in the blank runs was up to $\sim 120$ and $30 \mathrm{nmol}$ of $\mathrm{C}$ attributed to MTBSTFA and dimethylformamide (DMF) (33), respectively. If the background was similar for the analyzed samples of the mudstone, another source of $\mathrm{C}$ for combustion to $\mathrm{CO}_{2}$ during pyrolysis is required to account for the $>2 \mu \mathrm{mol}$ of evolved $\mathrm{CO}_{2}$ (Table 2). The estimated amount of MTBSTFA+DMF C in the blank runs is only 1-3\% of total evolved $\mathrm{CO}_{2}-\mathrm{C}$ from JK and CB analyses. Also, lower amounts of MTBSTFA C ( 18 nmol C) and DMF $\mathrm{C}(\sim 15 \mathrm{nmol} \mathrm{C})$ were detected in the CB-5 analysis (Table 2$)$, suggesting substantially less MTBSTFA and DMF were available for combustion to $\mathrm{CO}_{2}$ in this run due to implementation of the MTBSTFA-reduction protocol (14). These results indicate that most of the evolved $\mathrm{CO}_{2}$ from $\mathrm{CB}$ is not related to the known terrestrial $\mathrm{C}$ background in $\mathrm{SAM}$ and therefore additional $\mathrm{C}$ sources are required.

The initial amount of MTBSTFA and DMF C in the JK and CB analyses could have been higher than the levels measured in the empty cup blank because of additional adsorption of these volatiles to the solid-sample surface area after sample delivery. A triple-sized sample portion ( $135 \mathrm{mg}$ of sample) of JK (JK-3) was delivered to SAM to explore the effects of adsorption on measured $\mathrm{CO}_{2}$ releases. Estimates of the amount of $\mathrm{C}$ from MTBSTFA and DMF sources that could contribute to evolved $\mathrm{CO}_{2}$ for the JK-3 triple-portion sample show that the levels are similar (within error) compared to the single-portion JK sample analyses (Column 4 of Table 2), despite the potential for at least three times more MTBSTFA and DMF adsorption to the sample due to greater surface area. Also, the triple-portion sample evolved 2.4-3.5 times more $\mathrm{CO}_{2}$ (Table 2). MTBSTFA and DMF C likely contributed to a small portion of the evolved $\mathrm{CO}_{2}(21)$. The order-of-magnitude more $\mathrm{C}$ observed as $\mathrm{CO}_{2}$ in all samples and the near three-fold increase in $\mathrm{CO}_{2}$ observed for the triple portion run further demonstrate that the dominant $\mathrm{C}$ source for $\mathrm{CO}_{2}$ in the $\mathrm{JK}$ analyses came from the mudstone itself and not from known background C sources in SAM or Curiosity's sample acquisition and delivery system.

Another possible $\mathrm{C}$ source for the evolved $\mathrm{CO}_{2}$ is combusted martian indigenous and/or exogenous (meteoritic) organic matter in the mudstone. The Sheepbed mudstone has trace element compositions consistent with a meteoritic contribution that may have delivered 300-1,200 ppm organic C (7) and/or from weathering of igneous material (34). Also, metastable partially oxidized weathering products of martian organics of indigenous and/or exogenous origins such as mellitic acid (35) may have undergone decarboxylation during analysis in SAM. Laboratory analog experiments using SAMlike instrument conditions where mellitic acid and perchlorate salts were heated together have shown that the primary degradation products detected during pyrolysis are $\mathrm{CO}_{2}$ and $\mathrm{CO}(36,37)$. If mellitic acid or other benzenecarboxylates were present in Sheepbed, the organic degradation products may have decomposed to $\mathrm{CO}_{2}$ and other less-volatile 
degradation products, which could have gone undetected by SAM GCMS under the oven conditions employed for the pyrolysis experiments.

Overall, the potential $\mathrm{CO}_{2}$ sources include combustion of terrestrial organics resident in SAM (for a small portion of the evolved $\mathrm{CO}_{2}$ ), low-temperature acid dissolution of martian carbonates, and combustion and/or decarboxylation of indigenous and/or exogenous organic materials.

Evolved $\mathrm{SO}_{2}$ and $\mathrm{H}_{2} \mathrm{~S}$. Sulfur dioxide and $\mathrm{H}_{2} \mathrm{~S}$ evolved from the $\mathrm{JK}$ and $\mathrm{CB}$ samples during pyrolysis and both also evolved from the Rocknest aeolian material (10). The release of both reduced and oxidized $S$ volatiles suggests that reduced and oxidized $S$ species were present in all samples, or redox reactions in the SAM oven affected $S$ speciation. The total abundance of $\mathrm{S}$-bearing gases and the ratio of $\mathrm{SO}_{2} / \mathrm{H}_{2} \mathrm{~S}$ observed at JK were both $<30 \%$ of the values measured in Rocknest samples. Abundances of these gases were even lower in $\mathrm{CB}$ than in $\mathrm{JK}$, consistent with the lower bulk $\mathrm{S}$ composition measured by APXS $\left[1.57( \pm 0.03)\right.$ wt. $\% \mathrm{SO}_{3}$ for $\mathrm{CB}$ compared with $5.52( \pm 0.21)$ wt.\% $\mathrm{SO}_{3}$ for $\left.\mathrm{JK},(7)\right]$.

The evolved $\mathrm{SO}_{2}$ had a release peak temperature at $\sim 600-625{ }^{\circ} \mathrm{C}$, with a shoulder at $\sim 675^{\circ} \mathrm{C}$ (Figs 1a \& 2a). Several mineral sources of $\mathrm{S}$ are possible. CheMin detected anhydrite, bassanite, and pyrrhotite in both JK and $\mathrm{CB}$ and possible pyrite in JK (8). Pyrrhotite and possibly pyrite are candidate $\mathrm{S}$ sources for the $\mathrm{SO}_{2}$ and $\mathrm{H}_{2} \mathrm{~S}$ releases from $\mathrm{CB}$ and $\mathrm{JK}$. The lower-temperature $\mathrm{SO}_{2}$ and $\mathrm{HCl}$ evolutions occurred simultaneously with the release of $\mathrm{O}_{2}$ in $\mathrm{CB}$ (Fig. 2) and two additional $\mathrm{SO}_{2}$ release peaks were observed in the 500-800 ${ }^{\circ} \mathrm{C}$ range. Laboratory pyrolysis experiments of mixtures of pyrrhotite and Ca-perchlorate exhibited similar release patterns for $\mathrm{SO}_{2}, \mathrm{O}_{2}$, and $\mathrm{HCl}$ (Fig. 3b), however, the onset temperatures for their release is lower in $\mathrm{CB}$ consistent with a different perchlorate/chlorate salt (i.e., lower $\mathrm{O}_{2}$ release) or complex chemistry occurring in the SAM ovens that lowers the decomposition temperature of oxychlorine compounds (as discussed above). Thermal decomposition of Ca-sulfate is not likely to have contributed to the $\mathrm{SO}_{2}$ releases from JK and CB because they typically break down at higher temperatures than the maximum achievable by the SAM oven used in these experiments [>835 ${ }^{\circ} \mathrm{C}$ ].

Although pyrrhotite and pyrite are candidate S-bearing phases in $\mathrm{CB}$ and $\mathrm{JK}$, the evolved $\mathrm{SO}_{2}$ data are not uniquely diagnostic of these or any specific $\mathrm{S}$-bearing phases. Fe-sulfate minerals will evolve $\mathrm{SO}_{2}$ at $500-800{ }^{\circ} \mathrm{C}$ under conditions similar to SAM operational conditions. However, formation of Fe-sulfates requires strongly acidic conditions $(38,39)$ and Sheepbed is interpreted to record depositional and diagenetic environments at near-neutral $\mathrm{pHs}(1)$.

Evolution of $\mathrm{H}_{2} \mathrm{~S}$ occurred nearly simultaneously with evolution of $\mathrm{H}_{2}$ and high temperature $\mathrm{H}_{2} \mathrm{O}$ resulting from the dehydroxylation of the $2: 1$ phyllosilicate (Figs. 1 \& 2). $\mathrm{H}_{2} \mathrm{~S}$ may be a byproduct of the reaction of $\mathrm{H}_{2} \mathrm{O}$ with a Fe-sulfide such as pyrrhotite (Fig. 3b); however, it is possible that $\mathrm{SO}_{2}$ evolved at high temperatures is reduced in the presence of $\mathrm{H}_{2}$ to $\mathrm{H}_{2} \mathrm{~S}(40,41)$. $\mathrm{HCl}$ also evolves at higher temperatures (Figs. 1b, 2b), which can react with reduced $\mathrm{S}$ phases to form $\mathrm{H}_{2} \mathrm{~S}(42,43)$. 
Evolved N-bearing species. Potential N-bearing compounds evolved from JK and $\mathrm{CB}$ include $\mathrm{NO}, \mathrm{HCN}, \mathrm{CH}_{3} \mathrm{CN}, \mathrm{ClCN}, \mathrm{CF}_{3} \mathrm{CN}$ and $\mathrm{C}_{3} \mathrm{H}_{4} \mathrm{~F}_{3} \mathrm{NO}$. Evolved $\mathrm{NO}(\mathrm{m} / \mathrm{z} 30)$ in the JK and CB materials had abundances of 129-190 nmol and 190-389 nmol NO, respectively (Table 1). The abundances of NO in JK and CB blank runs were 70 and 12 nmol, respectively, and the predicted level of N contributed by MTBSTFA/DMF based on background measurements was typically less than $20 \mathrm{nmol} \mathrm{N}$. Hence, the source for the evolved NO appears to be within the mudstone. Other $\mathrm{N}$ compounds detected by SAM ( $\mathrm{HCN}, \mathrm{CH}_{3} \mathrm{CN}$, and $\mathrm{ClCN}$ ) are present at substantially lower abundances and they may be contributed by the MTBSTFA/DMF background in the SAM instrument. Both wet chemistry reagents contain one $\mathrm{N}$ atom per molecule of reagent. $\mathrm{CF}_{3} \mathrm{CN}$ is almost certain to be from decomposition of MTBSTFA because possible sources of $F$ in the martian samples (i.e., fluorapatite) will not decompose in the SAM temperature range. In addition, $\mathrm{HCN}$ and $\mathrm{CH}_{3} \mathrm{CN}$ have also been identified during laboratory pyrolysis of MTBSTFA and DMF in the presence of perchlorate run under similar operating conditions as SAM (21).

Organic Compounds. Pyrolysis of the JK and CB samples led to low temperature (125$350{ }^{\circ} \mathrm{C}$ ) release of chloromethane and dichloromethane that correlated with the release of $\mathrm{O}_{2}$ and 1,3-bis(1,1-dimethylethyl)-1,1,3,3-tetramethyldisiloxane, a known reaction product of MTBSTFA and $\mathrm{H}_{2} \mathrm{O}$ (Fig. S3). This correlation suggests that thermal degradation of the $\mathrm{O}_{2}$ source (most likely an oxychlorine compound, see above) is contributing to chlorination of $\mathrm{C}$ phases and/or the release of chlorinated hydrocarbons. Identification and quantification of these trace organic species by their characteristic $\mathrm{m} / \mathrm{z}$ values in EGA mode was enhanced and confirmed by bulk collection and GCMS identification (44) of volatiles on an adsorbent-resin hydrocarbon trap (Fig. 4, Fig. S4). Detection of chlorinated hydrocarbons by SAM in Rocknest samples (10,21), as well as supporting laboratory EGA and GCMS experiments conducted under SAM-like conditions, have shown that both chloromethane and dichloromethane are produced when MTBSTFA and DMF are heated in the presence of Ca- and $\mathrm{Mg}$-perchlorates (21). Therefore, reaction of MTBSTFA and DMF carbon with an oxychlorine compound is a likely source of some of the chloromethane and dichloromethane detected in JK and CB.

Empty-cup blank analyses prior to each sample set (Rocknest, JK and CB) showed low chloromethane $\mathrm{C}$ abundance ( $<7 \mathrm{nmol} \mathrm{C}$ including estimated error, via $\mathrm{EGA}$ ) and no detection of dichloromethane. In comparison to the blanks, single-portion runs of $\mathrm{JK}$ and $\mathrm{CB}$ consistently showed more abundant chloromethane and dichloromethane $\mathrm{C}$ [up to $\sim 6 \mathrm{x}$ more; range: $21( \pm 4)$ to $66( \pm 13) \mathrm{nmol} \mathrm{C}$, Table 2], whereas lower levels of chloromethane and dichloromethane $[12( \pm 2) \mathrm{nmol} C]$ were released from Rocknest single-portion samples, even though the total MTBSTFA C levels measured during pyrolysis of Rocknest were similar (within error) to the levels measured in JK and the CB-1 and CB-2 runs (Table 2). Furthermore, the JK-3 EGA analysis of a triple-portion sample released approximately two times more chloromethane + dichloromethane [127 $( \pm 25) \mathrm{nmol} \mathrm{C}$ ] than a single-portion JK analyses [38 $( \pm 8)$ to $66( \pm 13) \mathrm{nmol} \mathrm{C}]$ and JK-3 released trichloromethane $\left(\mathrm{CHCl}_{3}\right)$ and carbon tetrachloride $\left(\mathrm{CCl}_{4}\right)$, which were not previously detected in the blank or single-portion JK experimental runs (Table S2, Fig. 4). However, the increase in chlorinated products in JK-3 could also be explained by three times more sample (i.e., more oxychlorine compounds) compared to the single- 
portion JK runs. Trichloromethane and carbon tetrachloride were also detected by GCMS in both CB-3 and CB-5 at similar levels (Table S2). These data indicate that greater chlorinated hydrocarbon production is associated with the Sheepbed mudstone (compared with the Rocknest aeolian deposit) and with larger sample mass. However, the substantial reduction ( $\sim 50 \%$ ) in C abundance from MTBSTFA (and presumably DMF) in the CB-5 experiment compared with CB-3 (Fig. S5, Table 2) was matched by a $\sim 50 \%$ drop in chloromethane and dichloromethane detected by EGA $[10.2( \pm 2.0) \mathrm{nmol} \mathrm{C}$ and $0.7( \pm 0.2) \mathrm{nmol} \mathrm{C}$, respectively]. This suggests that martian organics may not be substantial contributors to these chloromethanes detected in CB samples.

Trace quantities of chloromethane and dichloromethane were also identified by the Viking 1 and 2 lander GCMS instruments (45,46). The Viking GCMS team attributed the chlorinated hydrocarbons to terrestrial sources including cleaning solvents, although the possibility that some of the chloromethane $\mathrm{C}$ was indigenous to Mars was not ruled out (46). Unlike SAM, the Viking GCMS instruments did not include an MTBSTFA/DMF wet chemistry experiment. Following the Phoenix perchlorate detection and subsequent laboratory experiments in which Atacama soils mixed with $1 \%$ by weight of $\mathrm{Mg}$-perchlorate produced chloromethane and dichloromethane at $500{ }^{\circ} \mathrm{C}$, the Viking chloromethane compounds have been attributed to the presence of perchlorates and indigenous organic carbon at the Viking landing sites (47). The hypothesis has been challenged (48) and debated (49).

The EGA and GCMS observations of varying chlorinated hydrocarbon abundances in JK and CB could result from any combination of the following: 1) chlorination of MTBSTFA and DMF or other unknown terrestrial C sources in SAM (instrument background) that were not identified during EGA or GCMS in the empty-cup blank runs; 2) chlorination of $\mathrm{C}$ contamination from the drill and/or sample handling chain; and 3) chlorination of martian or exogenous $\mathrm{C}$ phases in the Sheepbed mudstone.

Terrestrial contamination from the sample handling chain is unlikely because it was scrubbed multiple times with Rocknest scooped material prior to the first drilled sample at JK $(10,9)$. The GCMS abundances of chloromethane and dichloromethane measured in JK-4 were similar within error to the abundances of the chlorinated hydrocarbons identified in the second drill sample at $\mathrm{CB}$ (CB-2) run under identical conditions (Table S2). Therefore, if terrestrial C contamination from the drill was the primary source of $\mathrm{C}$ for these chlorinated hydrocarbons in $\mathrm{JK}-4$, their abundances measured in the CB-2 sample should have been reduced compared to JK-4 due to sample scrubbing of hardware surfaces and disposal of the JK sample from the sample processing system. This was not observed. Moreover, swabbed surfaces of Curiosity's sample acquisition and processing system were found to be organically clean prior to launch $(50,51)$ and only trace quantities $(\sim 0.1$ to $0.3 \mathrm{nmol})$ of perfluoroethene, a known pyrolysis product of Teflon that is within the drill system (52), were identified in the JK and CB EGA analyses.

Chlorinated hydrocarbons are likely produced in the SAM oven during heating of samples in the presence of $\mathrm{Cl}$ from the thermal decomposition of oxychlorine compounds. Some of the chlorinated hydrocarbon detected at JK and CB may be derived 
from the sample. The SAM data do not allow us to prove, or disprove, organic C contributions from Sheepbed to evolved chlorinated hydrocarbons and $\mathrm{CO}_{2}$ from the $\mathrm{JK}$ and CB samples. There are no conclusive EGA or GCMS observations of other organic molecules indigenous to the Sheepbed mudstone.

Preservation of Organics. Although the detection and identification of possible organic compounds in the Sheepbed mudstone is complicated by reactions in the SAM oven, the lack of a definitive detection of martian organics suggests that, if organics were deposited in the Sheepbed mudstone, organic alteration and destruction mechanisms may present the single-most fundamental challenge to the search for organics on Mars. Some organic compounds are expected on the surface of Mars. Exogenous delivery of meteoritic organics to the martian surface has been estimated as $10^{8} \mathrm{~g} \mathrm{C} /$ year (53) and may have been higher during periods of higher impact flux on the surface. Benzenecarboxylates derived from the oxidation of meteoritic organic matter on Mars could contribute up to $500 \mathrm{ppm}$ organic $\mathrm{C}$ by weight in the top meter of the martian regolith (35). Abiotic organic matter formed by igneous and/or hydrothermal processes $(34,54)$ is also expected to be embedded within basaltic minerals where it is protected from chemical oxidants in the environment. Consequently, at least a low concentration of organic compounds is likely in the source material for the Sheepbed mudstone. In addition, the distal fluvial to lacustrine depositional environment of Sheepbed (1) makes it a prime site for concentration of organic matter through sedimentary processes (2).

If organics were present, evaluating their fate during diagenesis becomes critical for understanding their molecular structures, distribution in sediments and SAM observations. The JK and CB samples experienced diagenesis, including the alteration of basaltic minerals to smectite and magnetite after deposition $(7,8)$. Organics may have been released during basaltic mineral alteration, and any reactive organic molecules present may have been incorporated into or adsorbed onto the forming smectite and magnetite. These types of mineral-organic associations could have enhanced the early preservation of organic matter. In addition, reducing conditions during deposition, as suggested by the presence of magnetite (7) would have favored early preservation. Subsequently, and at any time during burial, oxidants already present in disequilibrium with reduced phases or circulated into the rock may have contributed to the oxidative degradation of organic compounds that were deposited with the sediment or released from the altering igneous minerals. There is no evidence of mineral oxidation associated with the second diagenetic event that precipitated calcium sulfate minerals from fluids into the Sheepbed fracture network (7), and the bulk rock remained largely reducing based on the presence of magnetite and pyrrhotite in $\mathrm{JK}$ and $\mathrm{CB}$, and possible pyrite in JK (8). However, akaganeite in the samples may reflect oxidative weathering of pyrrhotite, which could indicate exposure of JK and CB to an oxidizing fluid in earlier diagenetic event(s) that may have degraded any organic compounds.

If any organic compounds remained throughout burial, they may have been altered by other mechanisms. The martian surface is subjected to strong ionizing radiation that can alter organic molecules (55) depending on the chemical and physical microenvironment of the host sediments (56). Ionizing radiation directly breaks chemical bonds in organic molecules and other chemicals producing a reactive pool of radicals and 
oxidants (e.g. $\mathrm{OH} \bullet, \mathrm{H}_{2} \mathrm{O}_{2}$, oxychlorine compounds). In the presence of mineral catalysts, these reactants can fully oxidize organic matter to $\mathrm{CO}, \mathrm{CO}_{2}$ and carbonates or produce partially oxidized organics such as acetate, oxalates, and other carboxylates that may survive in a metastable state on Mars (35). If exogenous or martian organic matter survived largely intact until removal of the overlying Gillespie sandstone, it may still have degraded or oxidized during surface exposure of the sampling site to ionizing radiation. Therefore, surface exposure age is also an important variable in the preservation of organics. Alternatively, the organics may have survived all of the martian processing that occurred naturally, only to be oxidized by oxide minerals or oxychlorine compounds at elevated temperatures in the SAM oven or, if sufficiently refractory, survive pyrolysis and pass undetected by SAM, as does most of the kerogen-like material in meteorites.

The complicated story of carbon on Mars is poorly understood. As of sol 370, SAM results support the presence of carbon source(s) in samples from the Sheepbed mudstone that contribute(s) to the production of chlorinated hydrocarbons and evolved $\mathrm{CO}_{2}$. There may be organic matter in these samples, but it has not been confirmed as martian.

\section{References and Notes:}

1. J. P. Grotzinger et al., A habitable fluvio-lucustrine environment at Yellowknife Bay, Gale crater, Mars. Science, submitted, this issue (2013).

2. R. E. Summons et al., Preservation of martian organic and environmental records: Final report of the Mars Biosignature Working Group. Astrobiology, 11, 157-181, doi: 10.1089/ast.2010.0506 (2011).

3. By definition, a mudstone is a fine-grained sedimentary rock composed of $50 \%$ or more of particles $<62 \mu \mathrm{m}$ (4). The Sheepbed mudstone is composed of $\sim 20 \%$ clay minerals and $\sim 30 \%$ amorphous materials (8).

4. P. E. Potter, J. B. Maynard, P. Depetris, Mud and Mudstones, Springer (2005)

5. P. R. Mahaffy et al. The Sample Analysis at Mars investigation and instrument suite. Space Sci. Rev. 70, 401-478, doi: 10.1007/s11214-012-9879-z (2012).

6. D. F. Blake et al. Characterization and calibration of the CheMin mineralogical instrument on Mars Science Laboratory. Space Sci. Rev. 170, 341-399, doi 10.1007/s11214-012-9905-1 (2012).

7. S. M. McLennan et al., Elemental geochemistry of sedimentary rocks in Yellowknife Bay, Gale Crater, Mars. Science, submitted, this issue (2013).

8. D. T. Vaniman et al., Mineralogy of a mudstone on Mars. Science, submitted, this issue (2013). 
9. D. F. Blake et al., Curiosity at Gale Crater, Mars: Characterization and Analysis of the Rocknest Sand Shadow. Science, 341, DOI: 10.1126/science.1239505 (2013).

10. L. A. Leshin et al., Volatile, isotope and organic analysis of martian fines with the Mars Curiosity Rover. Science, 341, DOI: 10.1126/science.1238937 (2013).

11. The term "soil"' is used here to denote any loose, unconsolidated materials that can be distinguished from rocks, bedrock, or strongly cohesive sediments. No implication for the presence or absence of organic materials or living matter is intended.

12. A. S. Yen et al. An Integrated View of the Chemistry and Mineralogy of Martian Soils. Nature, 436, 49-54 (2005).

13. K. H. Nealson, P. G. Conrad, Life: past, present and future. Phil. Trans. R. Soc. Lond., B. Millenium Issue, 1923 (1999).

14. Materials and methods are available as supplementary material on Science Online.

15. The mass of each sample portion delivered to SAM was estimated to be $45 \pm 18 \mathrm{mg}$, except for JK-3 where a triple portion (135 $\pm 31 \mathrm{mg})$ was delivered to the sample cup. Due to the known presence of the reaction products of MTBSTFA and possibly DMF in the SAM background due to a broken seal $(10,21)$, the analytical conditions of the first three JK samples were adjusted to boil off these molecules and associated reaction product by heating to $200-300{ }^{\circ} \mathrm{C}$ and holding the temperature for about 20 minutes. All evolved gases were analyzed directly by the QMS, but boil-off gases were vented thereafter in order to simplify GCMS analyses (14). The JK-4 sample was run under nominal conditions in which the pyrolysis oven was steadily heated from Mars ambient to $\sim 835^{\circ} \mathrm{C}$. Three samples of CB (CB-1, CB-2, and CB-3) were run under the same conditions as the JK-4 sample, i.e., under a continuous temperature ramp starting at Mars ambient conditions. Sample CB-5 SAM cup was preheated to $\sim 120^{\circ} \mathrm{C}$ and then moved into position directly under the solid sample inlet tube to receive the CB-5 portion from Curiosity's sample delivery system (14).

16. R. Gellert et al., Initial MSL APXS activities and observations at Gale crater, Mars. Paper presented at the $44^{\text {th }}$ Lunar Planet. Sci. Conf., Houston, TX, March 18-22, 2013.

17. J. L. Campbell et al., Quantitative in-situ determination of hydration of bright highsulfate martian soils. J. Geophys. Res.-Planets, 113, E06S11, doi.10.1029/2007JE002959 (2008).

18. Only the John Klein sample 4 (JK-4) EGA dataset is discussed in the text and shown in Fig. 1. The other three experiments were conducted with a pre-conditioning boil off that prevented systematic examination of the temperature of evolution below the boil-off temperature [approx. $\left.300^{\circ} \mathrm{C},(15)\right]$.

19. The three $S A M$ continuous temperature ramp analyses of the Cumberland material (CB-1, CB-2, and CB-3) revealed similar evolved gas patterns (Fig. S1), with 
variations in the abundances of gases evolved. Only the CB-2 sample is shown in Fig. 2 to represent the Cumberland evolved gas analysis. CB-5 EGA is not shown in this figure because it did not have the sample continuous temperature ramp conditions as the previous three $\mathrm{CB}$ runs.

20. M. M. Hecht et al., Detection of perchlorate and the soluble chemistry of martian soil at the Phoenix Lander site. Science, 325, 64-67, 10.1126/science.1172466 (2009).

21. D. P. Glavin et al., Evidence for perchlorates and the origin of chlorinated hydrocarbons detected by SAM at the Rocknest aeolian deposit in Gale Crater. $J$. Geophys. Res., 118, 1-19, doi:10.1002/jgre.20144 (2013).

22. G. Marvin, L. B. Woolaver, Thermal decomposition of perchlorates. Indust. Eng. Chem. 17, 474-476 (1945).

23. K. M. Cannon, B. Sutter, D. W. Ming, W. V. Boynton, R. Quinn. Perchlorate induced low temperature carbonate decomposition in the Mars Phoenix Thermal and Evolved Gas Analyzer (TEGA). Geophys. Res. Lett. 39, L13203, doi:10.1029/2012GL051952 (2012).

24. B. Sutter et al., The detection of carbonate in the martian soil at the Phoenix Landing site: A laboratory investigation and comparison with the Thermal and Evolved Gas Analyzer (TEGA) data. Icarus, 218, 290-296 (2012).

25. A. Migdał-Mikuli, J. Hetmańczyk, Thermal behavior of $\left[\mathrm{Ca}\left(\mathrm{H}_{2} \mathrm{O}\right)_{4}\right]\left(\mathrm{ClO}_{4}\right)_{2}$ and $\left[\mathrm{Ca}\left(\mathrm{NH}_{3} \mathrm{O}_{6}\right]\left(\mathrm{ClO}_{4}\right)_{2}\right.$. J. Therm. Anal. Calorimetry, 91, 529-534 (2008).

26. W. K. Rudloff, E. S. Freeman, Catalytic effect of metal oxides on thermal decomposition reactions. II. Catalytic effect of metal oxides on the thermal decomposition of potassium chlorate and potassium perchlorate as detected by thermal analysis methods. J. Phys. Chem., 74 (18), 3317-3324, doi: 10.1021/j100712a002 (1970).

27. J. Hanley, V. F. Chevrier, D. J. Berget, R. D. Adams, Chlorate salts and solutions on Mars. Geophys. Res. Lett. 39, L08201, doi:10.1029/ 2012GL051239 (2012).

28. R. C. Quinn, A. P. Zent, Peroxide-modified titanium dioxide: a chemical analog of putative martian soil oxidants. Origins Life Evolution Biospheres, 29, $59-72$ (1999).

29. A. S. Yen, S. S. Kim, M. H. Hecht, M. S. Frant, B. Murray, Evidence that the reactivity of the martian soil is due to superoxide ions. Science, 289, 1909-1912 (2000).

30. A. P. Zent, A. S. Ichimura, R. C. Quinn, H. K. Harding, The formation and stability of the superoxide radical $\left(\mathrm{O}_{2}^{-}\right)$on rock-forming minerals: Band gaps, hydroxylation state, and implications for Mars oxidant chemistry. J. Geophys. Res., 113, E09001, doi: 10.1029/2007JE003001 (2008). 
31. P. D. Archer, Jr., D. W. Ming, B. Sutter, The effects of instrument parameters and sample properties on thermal decomposition: interpreting thermal analysis data from Mars. Planet. Sci. 2:2, 21 p., doi:10.1186/2191-2521-2-2 (2013).

32. J. Jänchen, R. V. Morris, D. L. Bish, M. Janssen, U. Hellwig, The $\mathrm{H}_{2} \mathrm{O}$ and $\mathrm{CO}_{2}$ adsorption properties of phyllosilicate-poor palagonitic dust and smectites under martian environmental conditions, Icarus, 200, 463-467, (2009).

33. MTBSTFA (N-methyl-N-tert-butyl-dimethyl-silyl-trifluoro-acetamide) and dimethylformamide (DMF) have been identified in both empty-cup blank and Rocknest runs. See supplementary material on Science Online.

34. A. Steele et al., A reduced organic carbon source in martian basalts. Science, 337, 212-215, doi:10.1126/science.1220715 (2012).

35. S. A. Benner, K. G. Devine, L. N. Matveeva, D. H. Powell, The missing organic molecules on Mars. Proc. Nat. Acad. Sci. USA, 97(6), 2425-2430 (2000).

36. H. Steininger, F. Goesmann, W. Goetz, Influence of magnesium perchlorate on the pyrolysis of organic compounds in Mars analogue soils, Planetary and Space Science, 71(1), 9-17, http://dx.doi.org/10.1016/j.pss.2012.06.015.

37. D. W. Ming, et al., Combustion of organic molecules by the thermal decomposition of perchlorate salts: Implications for organics at the Mars Phoenix Scout landing site. Paper presented at the $40^{\text {th }}$ Lunar Planet. Sci. Conf., Houston, TX, March 23-27, 2009.

38. U. Schwertmann, R. M. Cornell, Iron oxides in the laboratory: Preparation and characterization. Wiley Online Library (2007).

39. J. M. Bigham, R. W. Fitzpatrick, D. G. Schulze, Iron oxides, in J. B. Dixon and D. G. Schulze (eds.), Soil Mineralogy with Environmental Applications, Soil Sci. Soc. Am. (2002).

40. V. S. Arutyunov et al., Kinetics of the reduction of sulfur-dioxide. 3. Formation of hydrogen-sulfide in the reaction of sulfur-dioxide with hydrogen. Kinetics Catalysis, 32(5), 1112-1115 (1991).

41. D. Binns, P. Marshall, An abinitio study of the reaction of atomic hydrogen with sulfur-dioxide. J. Chem. Phys., 95(7), 4940-4947, doi:10.1063/1.461710 (1991).

42. A. A. Baba, F. A. Adekola, O. O. Opaleye, R. B. Bale, Dissolution kinetics of pyrite ore by hydrochloric acid. J. Applied Sci. Technol., 16, 104-110 (2011).

43. T. R. Ingraham, H. W. Parsons, L. J. Cabri, Leaching of pyrrhotite with hydrochloric acid. Canadian Metallurgical Quarterly, 11(2), 407 (1972). 
44. The NIST/EPA/NIH Mass Spectral Database (NIST SRD Database No. 1A, Gaithersburg, MD, 2011) was used to identify chloromethane, dichloromethane, trichloromethane, and tetrachloromethane in GCMS measurements based on spectral lines in the gas chromatograms. The confirmation of these compounds aided in their identification and quantification in EGA.

45. K. Biemann et al., Search for organic and volatile inorganic compounds in two surface samples from the Chryse Planitia region of Mars. Science, 194, 72-76, doi: 10.1126/science.194.4260.72 (1976).

46. K. Biemann et al., The search for organic substances and inorganic volatile compounds in the surface of Mars. J. Geophys. Res., 82, 4641-4658 (1977).

47. R. Navarro-González, E. Vargas, J. de la Rosa, A. C. Raga, C. P. McKay, Reanalysis of the Viking results suggests perchlorate and organics at midlatitudes on Mars. $J$. Geophys. Res.-Planet, 115, E12, E12010 (2010).

48. K. Biemann, J. L. Bada, Comment on "Reanalysis of the Viking results suggests perchlorate and organics at midlatitudes on Mars" by Rafael Navarro-González et al., J. Geophys. Res., 116, E12001, doi:10.1029/2011JE003869 (2011).

49. R. Navarro-González, C. P. McKay, Reply to comment by Biemann and Bada on "Reanalysis of the Viking results suggests perchlorate and organics at midlatitudes on Mars.” J. Geophys. Res., 116, E12002, doi:10.1029/2011JE003880 (2011).

50. M. S. Anderson et al., In situ cleaning of instruments for the sensitive detection of organics on Mars. Rev Sci Instrum, 83(10), 105109 (2012).

51. J. E. Eigenbrode et al., Dectection of organic constituents including chloromethylpropene in the analysis of the Rocknest drift by Sample at Mars (SAM). Paper presented at the $44^{\text {th }}$ Lunar Planet. Sci. Conf., Houston, TX, March 18-22, 2013.

52. J. E. Eigenbrode et al., Fluorocarbon contamination from the drill on the Mars Science Laboratory: Potential science impact on detecting martian organics by Sample at Mars (SAM). Paper presented at the $44^{\text {th }}$ Lunar Planet. Sci. Conf., Houston, TX, March 18-22, 2013.

53. J. G. Flynn, The delivery of organic matter from asteroids and comets to the early surface of Mars. Earth, Moon, and Planets, 72, 469-474 (1996).

54. A. Steele et al., Graphite in the Martian Meteorite ALH 84001. Am. Mineral., 97, 1256-1259 (2012).

55. G. Kminek, J. Bada, The effect of ionizing radiation on the preservation of amino acids on Mars, Earth Planet. Sci. Lett., 245, 1-5 (2006). 
56. D. M. Hassler et al., The radiation environment on the surface of Mars measured with the Mars Science Laboratory's Curiosity rover, Science, submitted, this issue (2013).

57. A. E. Brunner et al., SAGE and GATES: How SAM scientists analyze GCMS data, Paper presented at the $44^{\text {th }}$ Lunar Planet. Sci. Conf., Houston, TX, March 18-22, 2013.

58. N. Gorocs, D. Mudri, J. Matyasi, J. Balla, The determination of GC-MS relative molar responses of some n-alkanes and their halogenated analogs. J. Chromatogr. Sci., 51(2), 138-145 (2013).

59. G. P. Karwasz, R. S. Brusa, A. Piazza, A. Zecca, Total cross sections for electron scattering on chloromethanes: Formulation of the additivity rule. Phys. Rev. A, 59(2), 1341-1347 (1999).

60. F. W. Lampe, J. L. Franklin, F. H. Field, Cross sections for ionization by electrons. J. Am. Chem. Soc., 79(23), 6129-6132 (1957).

61. J. L. Campbell et al., Calibration of the Mars Science Laboratory Alpha Particle Xray Spectrometer. Space Sci. Rev., 170, 319-340 (2012).

62. J. L. Campbell et al., Refinement of the Compton-Rayleigh scatter ratio method for use on the Mars Science Laboratory Alpha Particle X-ray Spectrometer. Nucl. Instrum. Meth. Physics Res., 302, 243-31 (2013).

63. B. Sutter et al., Detection of evolved carbon dioxide in the Rocknest eolian bedform by the Sam Analysis at Mars (SAM) instrument at the Mars Curiosity landing site. Paper presented at the $44^{\text {th }}$ Lunar Planet. Sci. Conf., Houston, TX, March 18-22, 2013.

64. B. Sutter et al., The detection of evolved oxygen from the Rocknest eolian bedform material by the Sample Analysis at Mars (SAM) instrument at the Mars Curiosity landing site. Paper presented at the $44^{\text {th }}$ Lunar Planet. Sci. Conf., Houston, TX, March 18-22, 2013.

65. H. V. Lauer, Jr., et al., Thermal and evolved gas analyses at reduced pressures: A mineral database for the Thermal and Evolved Gas Analyzer (TEGA). Paper presented at the $31^{\text {st }}$ Lunar Planet. Sci. Conf., Houston, TX, March 13-17, 2000.

Acknowledgments: The authors are indebted to the Mars Science Laboratory Project engineering and management teams for making this mission possible and enhancing science operations. Much of this research was carried out at the Jet Propulsion Laboratory, California Institute of Technology, under contract with the National Aeronautics and Space Administration (NASA). NASA provided support for the development of SAM. Data from these SAM experiments are archived in the Planetary Data System (pds.nasa.gov). Essential contributions to the successful operation of SAM on Mars and the acquisition of this data were provided by the SAM development, operations, and testbed teams. Development and operation of the SAM 
and APXS instruments were also supported by funds from the French Space Agency, CNES and the Canadian Space Agency. Work in the UK was funded by the UK Space Agency. B. L. E., J. L. E., K. F., D. P. G., J. E. G, K. E. M., S. M. M., J. M., P. B. N., and R. E. S. acknowledge funding support from the NASA ROSES MSL Participating Scientist Program. 


\section{Figures Captions:}

Fig. 1. Evolved gas analysis for a continuous ramp SAM pyrolysis of drill material $(<150 \mu \mathrm{m})$ from the Sheepbed mudstone John Klein 4 (JK-4) sample: A) Most-abundant evolved gases $\left[\mathrm{CO}_{2}\right.$ has been scaled up 3 times; $\mathrm{SO}_{2}$ and $\mathrm{O}_{2}$ have been scaled up 10 times]. B) Evolved gas traces for $\mathrm{H}_{2}, \mathrm{H}_{2} \mathrm{~S}, \mathrm{HCl}, \mathrm{CH}_{3} \mathrm{Cl}$, and $\mathrm{CH}_{2} \mathrm{Cl}_{2}\left[\mathrm{H}_{2} \mathrm{~S}\right.$ and $\mathrm{HCl}$ traces have been scaled up 35 times; $\mathrm{CH}_{3} \mathrm{Cl}$, and $\mathrm{CH}_{2} \mathrm{Cl}_{2}$ have been scaled up 100x]. Isotopologues were used to estimate species that saturated the QMS detector (m/z 12 for $\mathrm{CO}_{2}$ and $\mathrm{m} / \mathrm{z} 20$ for $\mathrm{H}_{2} \mathrm{O}$ ).

Fig. 2. Evolved gas analysis for a continuous ramp SAM pyrolysis of drill material $(<150 \mu \mathrm{m})$ from the Sheepbed mudstone Cumberland 2 (CB-2) sample: A) Mostabundant evolved gases $\left[\mathrm{CO}_{2}\right.$ and $\mathrm{SO}_{2}$ counts have been scaled up 3 and 15 times, respectively]. B) Evolved gas traces for $\mathrm{H}_{2}, \mathrm{H}_{2} \mathrm{~S}, \mathrm{HCl}, \mathrm{CH}_{3} \mathrm{Cl}$, and $\mathrm{CH}_{2} \mathrm{Cl}_{2}\left[\mathrm{H}_{2} \mathrm{~S}\right.$ and $\mathrm{HCl}$ traces have been scaled up 35 times; $\mathrm{CH}_{3} \mathrm{Cl}$ and $\mathrm{CH}_{2} \mathrm{Cl}_{2}$ have been scaled up 100 and 300 times, respectively]. Isotopologues were used to estimate species that saturated the QMS detector $\left(\mathrm{m} / \mathrm{z} 12\right.$ for $\mathrm{CO}_{2}$ and $\mathrm{m} / \mathrm{z} 20$ for $\left.\mathrm{H}_{2} \mathrm{O}\right)$.

Fig. 3. Major evolved gases from the John Klein (JK) and Cumberland (CB) samples compared with EGA of analog minerals under SAM-like oven operating conditions (14). A) Evolved $\mathrm{H}_{2} \mathrm{O}$ for nontronite, montmorillonite, and saponite compared with JK and CB evolved $\mathrm{H}_{2} \mathrm{O}$. B) Evolved $\mathrm{O}_{2}, \mathrm{SO}_{2}, \mathrm{HCl}$, and $\mathrm{H}_{2} \mathrm{~S}$ for CB-2 compared with pyrrhotite mixed with a Ca-perchlorate run under SAM-like operating conditions in laboratory experiments [Note $\mathrm{HCl}$ evolution coinciding with $\mathrm{O}_{2}$ release for $\mathrm{CB}-2$ and laboratory pyrrhotite/perchlorate experiments]. C) Evolved $\mathrm{O}_{2}$ for several perchlorate salts compared with John Klein and Cumberland evolved $\mathrm{O}_{2}$.

Fig. 4. SAM gas chromatogram of the major $\mathrm{m} / \mathrm{z}$, values of the chlorinated hydrocarbons detected in John Klein (JK) and Cumberland (CB) samples (cps = counts/s). A) JK Sample 3 (JK-3; triple portion) compared with JK-1 (single portion) and the JK blank. B) CB Sample 2 (CB-2, single portion) compared with the CB blank. C) The mass spectra generated for the GC peaks detected in JK-3 are shown in red and compared with the mass spectra for chloromethane $\left(\mathrm{CH}_{3} \mathrm{Cl}\right)$, dichloromethane $\left(\mathrm{CH}_{2} \mathrm{Cl}_{2}\right)$, and trichloromethane $\left(\mathrm{CHCl}_{3}\right)$ in black from NIST/EPA/NIH Mass Spectral Database (44).

Table Captions:

Table 1. Evolved gas abundances released during SAM pyrolysis runs of samples $(<150$ $\mu \mathrm{m}$ fraction) obtained from the John Klein and Cumberland drill holes. Rocknest aeolian material evolved gas abundances are provided for comparison with the Sheepbed mudstone materials.

Table 2. Abundances of terrestrial C from $N$-methyl- $N$-(tert-butyldimethylsilyl) trifluoroacetamide (MTBSTFA) reaction products and dimethylformamide (DMF) compared with the measured abundances of chloromethane $(\mathrm{CM})$, dichloromethane 
Ming et al., Volatile and Organic Compositions of Sedimentary Rocks on Mars

(DCM) and $\mathrm{CO}_{2}$ detected during SAM evolved gas analysis (EGA) by the mass spectrometer. 
Table 1. Evolved gas abundances released during SAM pyrolysis runs of samples $(<150$ $\mu \mathrm{m}$ fraction) obtained from the John Klein and Cumberland drill holes. Rocknest aeolian material evolved gas abundances are provided for comparison with the Sheepbed mudstone materials.

\begin{tabular}{|c|c|c|c|c|c|c|c|c|c|}
\hline & \multicolumn{4}{|c|}{ John Klein } & \multicolumn{3}{|c|}{ Cumberland } & \multirow[b]{2}{*}{ CB- 5} & \multirow{2}{*}{$\begin{array}{c}\text { Rocknest }^{@} \\
\text { Average of } \\
4 \text { runs }\end{array}$} \\
\hline & $\mathrm{JK}-1$ & $\mathrm{JK}-2$ & $\mathrm{JK}-3^{\#}$ & JK- 4 & CB-1 & CB-2 & CB-3 & & \\
\hline & \multicolumn{9}{|c|}{ Molar Abundances ( $\mu \mathrm{mol})$} \\
\hline $\mathrm{H}_{2} \mathrm{O}$ & $\begin{array}{l}57.4 \pm \\
32.7^{\&}\end{array}$ & $\begin{array}{c}54.2 \pm \\
30.8\end{array}$ & $\begin{array}{c}59.9 \pm \\
33.7\end{array}$ & $\begin{array}{c}44.7 \pm \\
25.0\end{array}$ & $\begin{array}{c}42.7 \pm \\
28.8\end{array}$ & $\begin{array}{c}54.0 \pm \\
29.5\end{array}$ & $\begin{array}{c}62.4 \pm \\
31.5\end{array}$ & $\begin{array}{c}45.0 \pm \\
25.4\end{array}$ & $55.1 \pm 35.3$ \\
\hline $\mathrm{CO}_{2}$ & $\begin{array}{c}7.0 \pm \\
1.9\end{array}$ & $\begin{array}{c}8.1 \pm \\
1.7\end{array}$ & $\begin{array}{c}6.6 \pm \\
1.6\end{array}$ & $\begin{array}{c}5.7 \pm \\
1.3\end{array}$ & $\begin{array}{c}2.0 \pm \\
0.5\end{array}$ & $\begin{array}{c}2.5 \pm \\
0.7\end{array}$ & $\begin{array}{c}3.1 \pm \\
0.6\end{array}$ & $\begin{array}{c}3.1 \pm \\
0.7\end{array}$ & $9.9 \pm 1.2$ \\
\hline $\mathrm{SO}_{2}$ & $\begin{array}{c}1.6 \pm \\
0.6\end{array}$ & $\begin{array}{c}1.4 \pm \\
0.1\end{array}$ & $\begin{array}{c}2.9 \pm \\
0.1\end{array}$ & $\begin{array}{c}2.0 \pm \\
0.0\end{array}$ & $\begin{array}{l}0.4 \pm \\
0.02\end{array}$ & $\begin{array}{c}1.3 \pm \\
0.2\end{array}$ & $\begin{array}{c}1.2 \pm \\
0.2\end{array}$ & $\begin{array}{c}1.4 \pm \\
0.2\end{array}$ & $12.2 \pm 0.9$ \\
\hline $\mathrm{O}_{2}$ & $\begin{array}{c}0.6 \pm \\
0.1\end{array}$ & $\begin{array}{c}0.8 \pm \\
0.1\end{array}$ & $\begin{array}{c}2.1 \pm \\
0.3\end{array}$ & $\begin{array}{c}0.9 \pm \\
0.1\end{array}$ & $\begin{array}{c}2.6 \pm \\
0.3\end{array}$ & $\begin{array}{c}8.4 \pm \\
1.0\end{array}$ & $\begin{array}{c}9.9 \pm \\
1.2\end{array}$ & $\begin{array}{c}11.2 \pm \\
1.4\end{array}$ & $3.9 \pm 0.2$ \\
\hline \multirow[t]{2}{*}{$\mathrm{H}_{2}$} & $\begin{array}{c}9.3 \pm \\
1.8 \\
\end{array}$ & $\begin{array}{c}5.1 \pm \\
1.0 \\
\end{array}$ & $\begin{array}{c}4.9 \pm \\
0.9 \\
\end{array}$ & $\begin{array}{c}5.3 \pm \\
1.0 \\
\end{array}$ & $\begin{array}{c}6.9 \pm \\
1.3 \\
\end{array}$ & $\begin{array}{c}11.6 \pm \\
2.2 \\
\end{array}$ & $\begin{array}{c}4.3 \pm \\
0.8 \\
\end{array}$ & $\begin{array}{c}4.1 \pm \\
0.8 \\
\end{array}$ & $\begin{array}{c}\text { not measured } \\
\text { directly }\end{array}$ \\
\hline & \multicolumn{9}{|c|}{$\%$} \\
\hline \multirow[t]{2}{*}{$\begin{array}{l}{ }^{\dagger} \text { High } \\
\text { Temp } \mathrm{H}_{2} \mathrm{O}\end{array}$} & $21 \pm 8$ & $21 \pm 8$ & $26 \pm 9$ & $34 \pm 11$ & $26 \pm 13$ & $31 \pm 8$ & $19 \pm 1$ & $31 \pm 11$ & \\
\hline & \multicolumn{9}{|c|}{ Molar Abundances (nmol) } \\
\hline $\mathrm{HCl}$ & $\begin{array}{c}58.5 \pm \\
26.1\end{array}$ & $\begin{array}{l}72.4 \pm \\
32.2\end{array}$ & $\begin{array}{c}536.1 \pm \\
238.7\end{array}$ & $\begin{array}{c}155.1 \pm \\
69.1\end{array}$ & $\begin{array}{c}44.1 \pm \\
19.6\end{array}$ & $\begin{array}{r}179.9 \\
\pm 80.1 \\
\end{array}$ & $\begin{array}{c}267.7 \pm \\
119.2\end{array}$ & $\begin{array}{c}584.9 \pm \\
260.5\end{array}$ & $36.5 \pm 10.4$ \\
\hline $\mathrm{H}_{2} \mathrm{~S}$ & $\begin{array}{c}79.0 \pm \\
35.2\end{array}$ & $\begin{array}{l}57.0 \pm \\
25.4\end{array}$ & $\begin{array}{c}95.2 \pm \\
42.4\end{array}$ & $\begin{array}{c}36.1 \pm \\
16.1\end{array}$ & $\begin{array}{c}18.7 \pm \\
8.3\end{array}$ & $\begin{array}{c}67.4 \pm \\
30.0\end{array}$ & $\begin{array}{c}38.9 \pm \\
17.3\end{array}$ & $\begin{array}{c}34.4 \pm \\
15.3\end{array}$ & $61.0 \pm 13.9$ \\
\hline \multirow[t]{2}{*}{$\mathrm{NO}$} & $\begin{array}{c}190 \pm \\
38\end{array}$ & $\begin{array}{c}188 \pm \\
38\end{array}$ & $\begin{array}{c}162 \pm \\
32\end{array}$ & $\begin{array}{c}129 \pm \\
26\end{array}$ & $\begin{array}{c}190 \pm \\
38\end{array}$ & $\begin{array}{c}331 \pm \\
66\end{array}$ & $\begin{array}{c}389 \pm \\
78\end{array}$ & $\begin{array}{l}374 \pm \\
75\end{array}$ & $175 \pm 40$ \\
\hline & \multicolumn{9}{|c|}{ Sample Weight (\%) } \\
\hline $\mathrm{H}_{2} \mathrm{O}$ & $\begin{array}{c}2.3 \pm \\
1.6\end{array}$ & $\begin{array}{l}2.2 \pm \\
1.5\end{array}$ & $\begin{array}{l}2.4 \pm \\
1.5\end{array}$ & $\begin{array}{c}1.8 \pm \\
1.2\end{array}$ & $\begin{array}{l}1.7 \pm \\
1.3\end{array}$ & $\begin{array}{c}2.2 \pm \\
1.5\end{array}$ & $\begin{array}{c}2.5 \pm \\
1.6\end{array}$ & $\begin{array}{l}1.8 \pm \\
1.2\end{array}$ & $2.0 \pm 1.3$ \\
\hline $\mathrm{CO}_{2}$ & $\begin{array}{c}0.7 \pm \\
0.3\end{array}$ & $\begin{array}{c}0.8 \pm \\
0.4 \\
\end{array}$ & $\begin{array}{c}0.6 \pm \\
0.2 \\
\end{array}$ & $\begin{array}{c}0.6 \pm \\
0.3\end{array}$ & $\begin{array}{c}0.2 \pm \\
0.09 \\
\end{array}$ & $\begin{array}{c}0.2 \pm \\
0.1\end{array}$ & $\begin{array}{c}0.3 \pm \\
0.1\end{array}$ & $\begin{array}{c}0.3 \pm \\
0.1 \\
\end{array}$ & $0.9 \pm 0.1$ \\
\hline $\begin{array}{l}\mathrm{SO}_{3} \\
\text { equivalent }\end{array}$ & $\begin{array}{c}0.3 \pm \\
0.1 \\
\end{array}$ & $\begin{array}{c}0.2 \pm \\
0.1\end{array}$ & $\begin{array}{l}0.5 \pm \\
0.05\end{array}$ & $\begin{array}{c}0.4 \pm \\
0.1\end{array}$ & $\begin{array}{c}0.1 \pm \\
0.0\end{array}$ & $\begin{array}{c}0.2 \pm \\
0.1\end{array}$ & $\begin{array}{c}0.2 \pm \\
0.09\end{array}$ & $\begin{array}{c}0.2 \pm \\
0.10\end{array}$ & $2.0 \pm 0.2$ \\
\hline $\begin{array}{l}\mathrm{Cl}_{2} \mathrm{O}_{7} \\
\text { equivalent }\end{array}$ & $\begin{array}{c}0.07 \pm \\
0.03\end{array}$ & $\begin{array}{c}0.09 \pm \\
0.04\end{array}$ & $\begin{array}{c}0.24 \pm \\
0.04\end{array}$ & $\begin{array}{c}0.10 \pm \\
0.04\end{array}$ & $\begin{array}{c}0.3 \pm \\
0.1\end{array}$ & $\begin{array}{c}1.0 \pm \\
0.4\end{array}$ & $\begin{array}{c}1.2 \pm \\
0.5\end{array}$ & $\begin{array}{c}1.3 \pm \\
0.5\end{array}$ & $0.4 \pm 0.1$ \\
\hline
\end{tabular}

${ }^{\&}$ Errors reported for molar abundances of $\mathrm{CO}_{2}, \mathrm{SO}_{2}$, and $\mathrm{O}_{2}$ are the $2 \sigma$ standard deviation from the mean of calculations done using different $\mathrm{m} / \mathrm{z}$ values for the same species. $\mathrm{H}_{2} \mathrm{O}$ error bars are based on the uncertainty in pre-launch water abundance calibration. Errors for other species include the uncertainty in differences in ionization efficiency between masses with a calibrated mol/counts value and uncalibrated values (10). Weight \% values were calculated using an estimated sample mass of $45 \pm 18 \mathrm{mg}$ $(2 \sigma)$, with errors propagated including the uncertainty in molar abundance $(10)$.

${ }^{\circledR}$ Average of four SAM runs of the Rocknest aeolian material (10).

${ }^{\dagger} \mathrm{High}$ temperature $\mathrm{H}_{2} \mathrm{O}$ is the percentage of the $\mathrm{H}_{2} \mathrm{O}$ released between 450 and $835^{\circ} \mathrm{C}$, which is the temperature region for dehydroxylation of a 2:1 phyllosilicate, compared to the total $\mathrm{H}_{2} \mathrm{O}$ released. 
\#Three sample portions ( $135 \pm 31 \mathrm{mg})$ of John Klein drill material were delivered to SAM for the JK-3 experimental run. The numbers in this column have been normalized to 1 sample portion $(45 \mathrm{mg})$. 
Table 2. Abundances of terrestrial C from $N$-methyl- $N$-(tert-butyldimethylsilyl) trifluoroacetamide (MTBSTFA) reaction products and dimethylformamide (DMF) compared with the measured abundances of chloromethane (CM), dichloromethane (DCM) and $\mathrm{CO}_{2}$ detected during SAM evolved gas analysis (EGA) by the mass spectrometer.

\begin{tabular}{|c|c|c|c|c|c|c|}
\hline Sample & $\begin{array}{c}\text { Total } \\
\text { detected } \\
\text { MTBSTFA- } \\
\text { derived C } \\
(\mu \mathrm{mol}){ }^{*}\end{array}$ & $\begin{array}{c}\text { Estimate } \\
\text { of missing } \\
\text { DMF C } \\
(\mu \mathrm{mol})^{\dagger}\end{array}$ & $\begin{array}{c}\text { Total CM } \\
+\underset{(\mu \mathrm{CM} \mathrm{C}}{ } \\
(\mu \mathrm{mol})\end{array}$ & $\begin{array}{c}\text { Estimated } \\
\text { amount of } \\
\text { MTBSTFA- } \\
\text { and DMF- } \\
\text { derived C } \\
\text { for } \\
\text { combustion } \\
(\mu \mathrm{mol})^{\S}\end{array}$ & $\begin{array}{c}\text { Total } \\
\mathrm{CO}_{2} \\
(\boldsymbol{\mu m o l})\end{array}$ & $\begin{array}{c}\text { Estimated } \\
\text { MTBSTFA + } \\
\text { DMF C } \\
\text { combustion } \\
\text { in analysis } \\
\text { relative to } \\
\text { total } \mathrm{CO}_{2}{ }^{\ddagger}\end{array}$ \\
\hline JK Blank & $0.120 \pm 0.024$ & $0.030 \pm 0.006$ & $0.005 \pm 0.001$ & $\approx 0$ & $\approx 0$ & $\approx 0 \%$ \\
\hline JK-1 & $0.051 \pm 0.010$ & $0.013 \pm 0.003$ & $0.066 \pm 0.013$ & $0.086 \pm 0.043$ & $7.0 \pm 1.9$ & $1.2 \pm 0.7 \%$ \\
\hline JK-2 & $0.044 \pm 0.009$ & $0.011 \pm 0.002$ & $0.061 \pm 0.012$ & $0.095 \pm 0.041$ & $8.1 \pm 1.7$ & $1.2 \pm 0.5 \%$ \\
\hline $\begin{array}{c}\text { JK-3 } \\
\text { (3x portion) }\end{array}$ & $0.071 \pm 0.014$ & $0.018 \pm 0.004$ & $0.127 \pm 0.025$ & $0.061 \pm 0.048$ & $19.8 \pm 4.8$ & $0.3 \pm 0.3 \%$ \\
\hline JK-4 & $0.047 \pm 0.009$ & $0.012 \pm 0.002$ & $0.038 \pm 0.008$ & $0.091 \pm 0.041$ & $5.7 \pm 1.3$ & $1.6 \pm 0.7 \%$ \\
\hline CB Blank & $0.097 \pm 0.019$ & $0.025 \pm 0.005$ & $0.006 \pm 0.001$ & $\approx 0$ & $\approx 0$ & $\approx 0 \%$ \\
\hline CB-1 & $0.068 \pm 0.014$ & $0.017 \pm 0.003$ & $0.025 \pm 0.005$ & $0.037 \pm 0.041$ & $2.0 \pm 0.2$ & $1.9 \pm 2.1 \%$ \\
\hline $\mathrm{CB}-2$ & $0.041 \pm 0.008$ & $0.010 \pm 0.002$ & $0.022 \pm 0.004$ & $0.071 \pm 0.034$ & $2.5 \pm 0.4$ & $2.8 \pm 1.4 \%$ \\
\hline CB-3 & $0.032 \pm 0.006$ & $0.008 \pm 0.002$ & $0.021 \pm 0.004$ & $0.082 \pm 0.032$ & $3.1 \pm 0.3$ & $2.7 \pm 1.1 \%$ \\
\hline CB-5 & $0.018 \pm 0.004$ & $0.005 \pm 0.001$ & $0.011 \pm 0.002$ & n.d. & $3.1 \pm 0.7$ & n.d. \\
\hline RN Blank & $0.078 \pm 0.016$ & $0.020 \pm 0.004$ & $0.002 \pm 0.001$ & $\approx 0$ & $\approx 0$ & $\approx 0 \%$ \\
\hline $\begin{array}{c}\text { RN1-4 } \\
\text { (average) }\end{array}$ & $0.058 \pm 0.012$ & $0.015 \pm 0.003$ & $0.012 \pm 0.002$ & $0.025 \pm 0.035$ & $9.9 \pm 1.2$ & $0.3 \pm 0.4 \%$ \\
\hline
\end{tabular}

"Total MTBSTFA C value in $\mu$ mol determined from the sum of the EGA measured abundances of silylated products: tert-butyldimethylsilanol, 1,3-bis(1,1-dimethylethyl)-1,1,3,3tetramethyldisiloxane, and tert-butyldimethylfluorosilane, plus the mole fraction of $\mathrm{C}$ from 2,2,2trifluoro- $N$-methylacetamide in MTBSTFA relative to the sum of the silylated products.

${ }^{\dagger}$ DMF was not identified during pyrolysis by EGA or GCMS. However, the amount of DMF C was estimated from the total measured MTBSTFA $C$ and the molar ratio of DMF/MTBSTFA carbon $(0.25)$ that was originally loaded into the wet chemistry cups, to address a worst-case scenario.

${ }^{\S}$ Estimated amount of combusted MTBSTFA- and DMF-derived C equals the amount of $\mathrm{C}$ in the blank from these sources minus the amount of $\mathrm{C}$ from these sources that was observed and calculated for each solid sample run.

${ }^{t}$ Percentage of the total MTBSTFA and DMF carbon in the preceding blank analysis, assumed to be representative of the MTBSTFA and DMF derived carbon available for combustion to $\mathrm{CO}_{2}$, compared to total $\mathrm{CO}_{2}$ measured in the sample runs.

n.d. = values could not be determined since a comparable blank run was not carried out under the same experimental conditions as CB-5. 

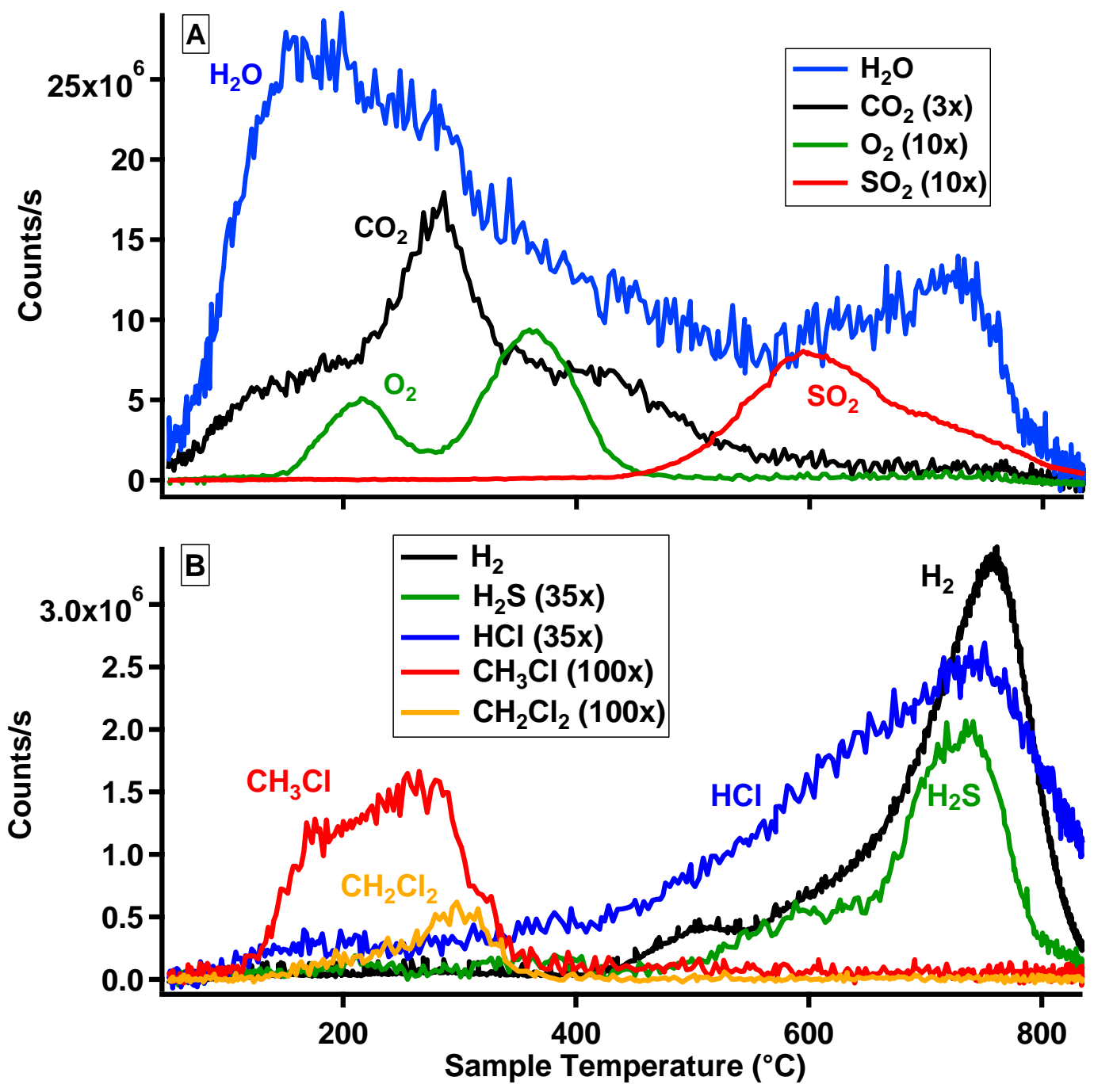

Fig. 1. Evolved gas analysis for a continuous ramp SAM pyrolysis of drill material $(<150 \mu \mathrm{m})$ from the Sheepbed mudstone John Klein 4 (JK-4) sample: A) Most-abundant evolved gases $\left[\mathrm{CO}_{2}\right.$ has been scaled up 3 times; $\mathrm{SO}_{2}$ and $\mathrm{O}_{2}$ have been scaled up 10 times]. B) Evolved gas traces for $\mathrm{H}_{2}, \mathrm{H}_{2} \mathrm{~S}, \mathrm{HCl}, \mathrm{CH}_{3} \mathrm{Cl}$, and $\mathrm{CH}_{2} \mathrm{Cl}_{2}\left[\mathrm{H}_{2} \mathrm{~S}\right.$ and $\mathrm{HCl}$ traces have been scaled up 35 times; $\mathrm{CH}_{3} \mathrm{Cl}$, and $\mathrm{CH}_{2} \mathrm{Cl}_{2}$ have been scaled up 100x]. Isotopologues were used to estimate species that saturated the QMS detector $(\mathrm{m} / \mathrm{z} 12$ for $\mathrm{CO}_{2}$ and $\mathrm{m} / \mathrm{z} 20$ for $\mathrm{H}_{2} \mathrm{O}$ ). 

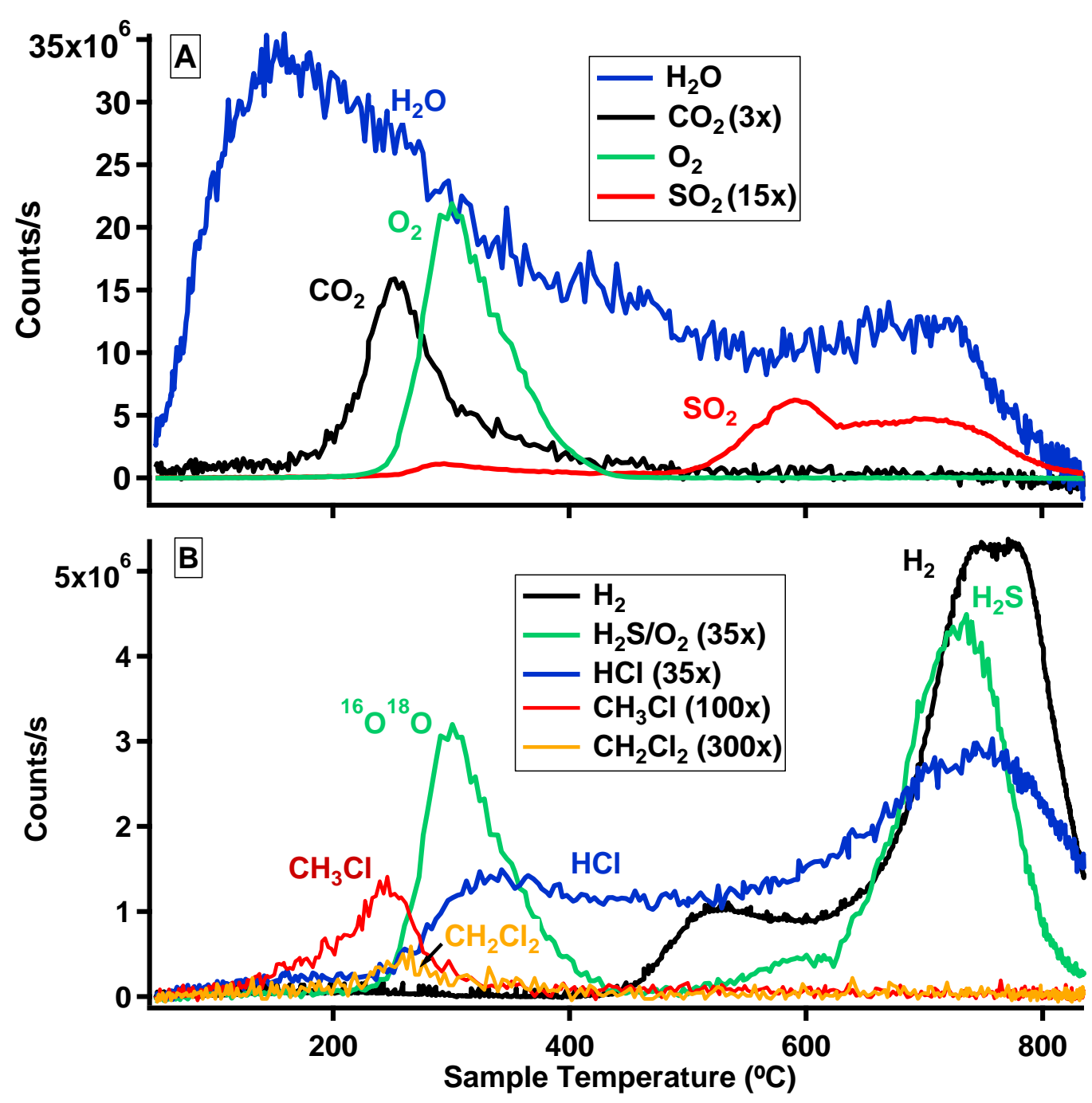

Fig. 2. Evolved gas analysis for a continuous ramp SAM pyrolysis of drill material $(<150 \mu \mathrm{m})$ from the Sheepbed mudstone Cumberland 2 (CB-2) sample: A) Mostabundant evolved gases $\left[\mathrm{CO}_{2}\right.$ and $\mathrm{SO}_{2}$ counts have been scaled up 3 and 15 times, respectively]. B) Evolved gas traces for $\mathrm{H}_{2}, \mathrm{H}_{2} \mathrm{~S}, \mathrm{HCl}, \mathrm{CH}_{3} \mathrm{Cl}$, and $\mathrm{CH}_{2} \mathrm{Cl}_{2}\left[\mathrm{H}_{2} \mathrm{~S}\right.$ and $\mathrm{HCl}$ traces have been scaled up 35 times; $\mathrm{CH}_{3} \mathrm{Cl}$ and $\mathrm{CH}_{2} \mathrm{Cl}_{2}$ have been scaled up 100 and 300 times, respectively]. Isotopologues were used to estimate species that saturated the QMS detector $\left(\mathrm{m} / \mathrm{z} 12\right.$ for $\mathrm{CO}_{2}$ and $\mathrm{m} / \mathrm{z} 20$ for $\left.\mathrm{H}_{2} \mathrm{O}\right)$. 

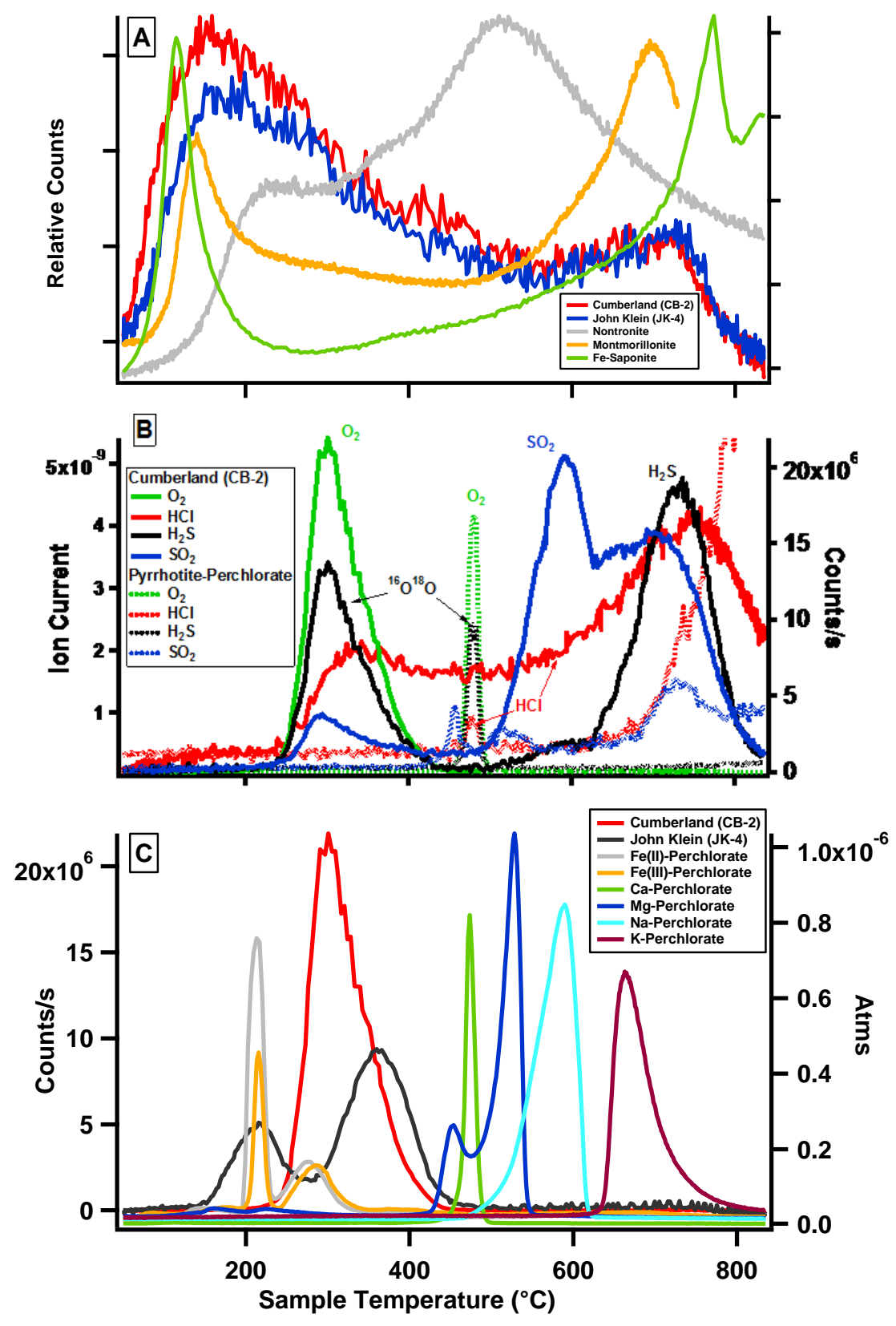

Fig. 3. Major evolved gases from the John Klein (JK) and Cumberland (CB) samples compared with EGA of analog minerals under SAM-like oven operating conditions (14). A) Evolved $\mathrm{H}_{2} \mathrm{O}$ for nontronite, montmorillonite, and saponite compared with $\mathrm{JK}$ and CB evolved $\mathrm{H}_{2} \mathrm{O}$. B) Evolved $\mathrm{O}_{2}, \mathrm{SO}_{2}, \mathrm{HCl}$, and $\mathrm{H}_{2} \mathrm{~S}$ for CB-2 compared with pyrrhotite mixed with a Ca-perchlorate run under SAM-like operating conditions in laboratory experiments [Note $\mathrm{HCl}$ evolution coinciding with $\mathrm{O}_{2}$ release for $\mathrm{CB}-2$ and laboratory pyrrhotite/perchlorate experiments]. C) Evolved $\mathrm{O}_{2}$ for several perchlorate salts compared with John Klein and Cumberland evolved $\mathrm{O}_{2}$. 
A)

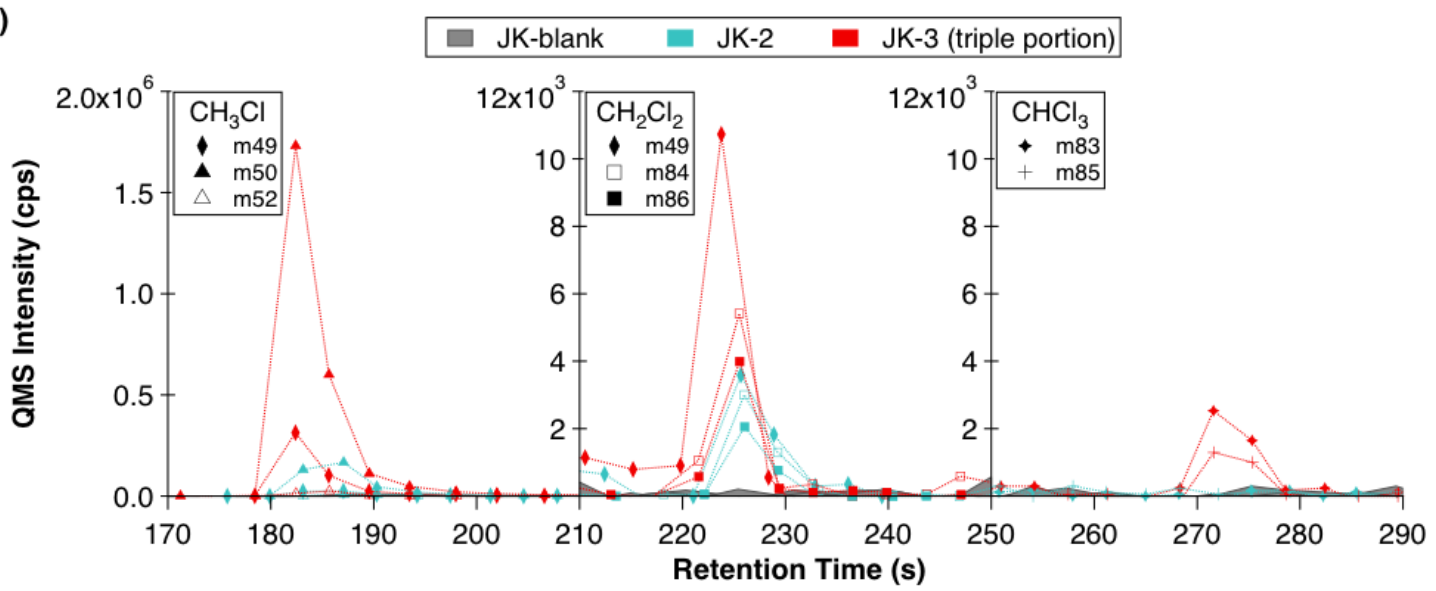

B)

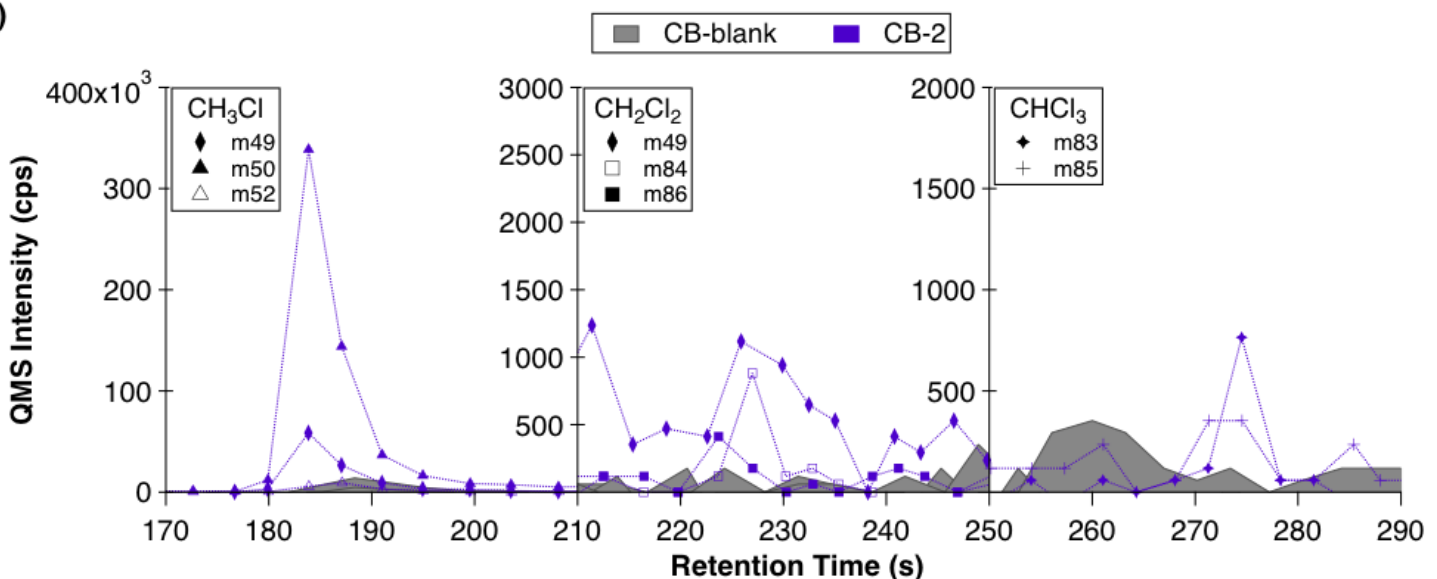

C)

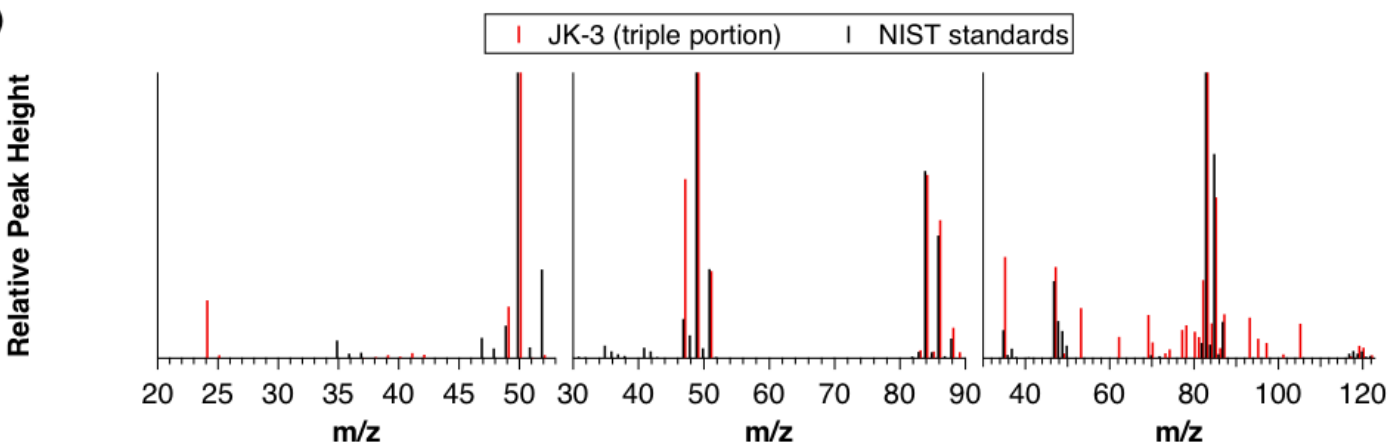

Fig. 4. SAM gas chromatogram of the major $\mathrm{m} / \mathrm{z}$ values of the chlorinated hydrocarbons detected in John Klein (JK) and Cumberland (CB) samples (cps = counts/s). A) JK Sample 3 (JK-3; triple portion) compared with JK-1 (single portion) and the JK blank. B) CB Sample 2 (CB-2, single portion) compared with the CB blank. C) The mass spectra generated for the GC peaks detected in JK-3 are shown in red and compared with the mass spectra for chloromethane $\left(\mathrm{CH}_{3} \mathrm{Cl}\right)$, dichloromethane $\left(\mathrm{CH}_{2} \mathrm{Cl}_{2}\right)$, and trichloromethane $\left(\mathrm{CHCl}_{3}\right)$ in black from NIST/EPA/NIH Mass Spectral Database (44). 


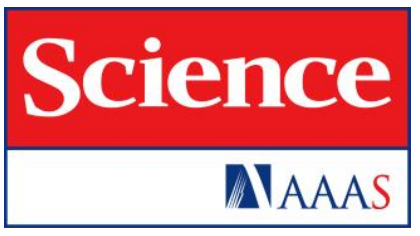

\section{Supplementary Materials for}

\section{Volatile and Organic Compositions of a Sedimentary Rock in Yellowknife Bay, Gale crater, Mars}

D. W. Ming, P. D. Archer, Jr., D. P. Glavin, J. L. Eigenbrode, H. B. Franz, B. Sutter, A. E. Brunner, J. C. Stern, C. Freissinet, A. C. McAdam, P. R. Mahaffy, M. Cabane, P. Coll, J. L. Campbell, S. K. Atreya, P. B. Niles, J. F. Bell III, D. L. Bish, W. B. Brinckerhoff, A. Buch, P. G. Conrad, D. J. Des Marais, B. L. Ehlmann, A. G. Fairén, K. Farley, G. J. Flesch, P. Francois, R. Gellert, J. A. Grant, J. P. Grotzinger, S. Gupta, K. E. Herkenhoff, J. A. Hurowitz, L. A. Leshin, K. W. Lewis, S. M. McLennan, K. E. Miller, J. Moersch, R. V. Morris, R. Navarro-González, A. A. Pavlov, G. M. Perrett, I. Pradler, S. W. Squyres, R. E. Summons, A. Steele, E. M. Stolper, D. Y. Sumner, C. Szopa, S. Teinturier, M. G. Trainer, A. H. Treiman, D. T. Vaniman, A. R. Vasavada, C. R. Webster, J. J. Wray, R. A. Yingst and the MSL Science Team.

*Corresponding to: douglas.w.ming@ nasa.gov

This PDF file includes:

Materials and Methods

Figs S1 to S6

Tables S1 to S3

References (57-65)

MSL Science Team Author List 
Materials and Methods

SAM Instrument Overview and Operations: The Sample Analysis at Mars (SAM) instrument suite supports the Mars Science Laboratory (MSL) mission and sits inside the Curiosity rover at Gale Crater on Mars. The SAM instruments are a quadrupole mass spectrometer (QMS), a tunable laser spectrometer (TLS), and a 6-column gas chromatograph (GC) with thermal conductivity detectors (TCDs) (5). These three instruments share a solid sample and gas processing system to generate complementary compositional and isotopic observations on each sample delivered by the rover's Sample Acquisition/Sample Processing and Handling (SA/SPaH) hardware to a SAM solid sample inlet tube or ingested directly through a gas inlet. An empty quartz cup is placed inside the pyrolysis oven before each analysis. The gas processing system, hydrocarbon trap, and empty cup are subsequently purged with He and heated to release any residual volatiles in the system to precondition and clean SAM. Before each set of solid samples from a site is delivered to SAM, an empty cup is exposed to the sample manipulation system for a simulated sample handoff and then placed back in the oven for pyrolysis evolved gas analysis (EGA), tunable laser spectrometer, and gas chromatography mass spectrometry (GCMS) measurements of the SAM background (i.e., the blank).

After the blank runs, samples from the John Klein (JK) and Cumberland (CB) that had been previously drilled and sieved $<150 \mu \mathrm{m}$ particle size fraction were delivered to SAM from a portion tube with a $76 \mathrm{~mm}^{3}$ volume. These samples were heated under the same conditions as the empty-cup blank runs to thermally evolve gases for processing and analysis. These volatiles are the result of the following processes often happening concurrently: 1) desorption of surface-adsorbed volatiles, 2) mineral and/or organic thermal decomposition, and 3 ) thermochemical reactions among chemical components.

SAM performs EGA of all evolved gases by direct QMS detection. Isotopic compositions are determined using both the QMS and the TLS. The TLS is tuned primarily for the measurement of $\mathrm{CO}_{2}, \mathrm{H}_{2} \mathrm{O}$, and $\mathrm{CH}_{4}$ and carbon, oxygen, and hydrogen isotopic measurements of select temperature cuts of evolved gas. TLS results are beyond the scope of this paper. Details of the TLS measurements are described elsewhere (5). Measurements of volatile organic compounds can be performed with the QMS alone or when it is coupled to the gas chromatograph (GC). SAM heated each sample to $\geq 835^{\circ} \mathrm{C}$ at a rate of $35{ }^{\circ} \mathrm{C} / \mathrm{min}$ with a He carrier gas (99.999\% purity) flow rate of $\sim 0.8$ standard $\mathrm{cm}^{3}$ per minute $(\mathrm{sccm})$ and at an oven pressure of $\sim 25$ mbar. During the pyrolysis heating, the SAM QMS analyzed abundances of gases across the entire temperature range, and select temperature ranges of the evolved gases in each run were sent to TLS and GC for analysis (Table S1).

For the SAM GCMS analyses, a cut of the gases evolved was diverted through the SAM hydrocarbon trap (i.e., the GC hydrocarbon trap temperature cut, Table S1). The hydrocarbon trap consists of three adsorbents in series: $0.49 \mathrm{~g}$ of $0.38-\mathrm{mm}$ non-porous silica beads, $0.079 \mathrm{~g}$ of 60/80 mesh Tenax TA (porous 2,6-diphenylene oxide polymer resin adsorbent), and $0.11 \mathrm{~g}$ of 60/80 Carbosieve $\mathrm{G}$ (graphitized carbon). The hydrocarbon trap was set to an initial temperature of $\sim 5^{\circ} \mathrm{C}$ with thermoelectric coolers prior to exposing the trap to the pyrolysis oven outflow. The gas manifold was then pressurized to $\sim 800 \mathrm{mb}$ with He. After purging GC column 5 (MXT-CLP, WCOT 
polydimethylsiloxane with phenyl and cyanopropyl stationary phase: 30-m length, 0.25$\mathrm{mm}$ internal diameter, 0.25 - $\mu \mathrm{m}$ film thickness) with He, the hydrocarbon trap was heated to $\sim 300{ }^{\circ} \mathrm{C}$ for 4 min under He flow in the opposite direction of trapping and the volatiles released were directed to a smaller injection trap containing $0.016 \mathrm{~g}$ of Tenax TA at the front of column. Rapid heating of the injection trap to $\sim 300{ }^{\circ} \mathrm{C}$ marked the start of chromatography set at an initial column temperature of $30{ }^{\circ} \mathrm{C}$ followed by a $10{ }^{\circ} \mathrm{C} / \mathrm{min}$ heating ramp to $220{ }^{\circ} \mathrm{C}$ under a He flow of $\sim 0.4 \mathrm{sccm}$. Volatiles eluting from the column were detected by a thermal conductivity detector (TCD) and by the QMS on a fraction of gas diverted into the mass spectrometer (split ratio to QMS of $\sim 250: 1$ calculated from a SAM gas flow model). The flow restrictor split design prevents the vacuum of the mass spectrometer with its miniaturized pump from being overloaded with He carrier gas while maintaining the required sensitivity for trace organics detection. For the JK and CB 1-3 analyses, the QMS scanned for ions in an $m / z$ range of 2-535 using the Smart Scanning algorithm previously described (5). Using the knowledge gained from these scans, a reduced set of masses that showed signal during past runs were identified and a "vector scan" (selective ion mode) scan was used for the CB-5 run to increase the sampling frequency of these masses. Operating in this mode increases our time resolution by a factor of 2 to 5 . For both of these scanning modes, a typical sensitivity limit for GCMS analysis based on hydrocarbon gas calibration standards (benzene and hexane) tested on the SAM Flight Module was $\sim 10^{-12}$ mol (5).

Solid Sample Delivery: At JK and CB, individual portions of the fines from the drilled materials were delivered to SAM multiple times and placed in separate quartz-glass cups. Most of the JK sample runs and all of the sample runs of CB analyzed a single portion of sample delivered by the SA/SPaH system to SAM. The mass of the sample portions delivered to SAM was not measured in situ. However, based on the volume of sample per portion delivered during repeated experimental tests on Earth with analog materials using the MSL SA/SPaH testbed and theoretical models to approximate the behavior of the SA/SPaH system in the martian environment, a mass of $45 \pm 18 \mathrm{mg}$ ( $2 \sigma$ standard deviation) per portion delivered to SAM was estimated. For the JK-3 run, a triple portion of powdered sample was delivered to SAM corresponding to a mass of $\sim 135 \pm 31 \mathrm{mg}$.

\section{MTBSTFA reduction and other analytical modifications used for the JK blank and} the JK-1, JK-2, and JK-3 samples: For the JK blank and the first three sample analyses of the JK drill sample, gases evolved up to an estimated temperature of $\sim 220^{\circ} \mathrm{C}$ during cup heating were vented to reduce the levels of MTBSTFA on the sample cup (Table $\mathrm{S} 1$ ). The evolved gases from this temperature range were measured by the QMS. GC hydrocarbon trap and TLS cuts used in these pyrolysis experiments were only taken after boiloff at cup temperatures $>240^{\circ} \mathrm{C}$. These analytical modifications were employed to reduce the background in the SAM GCMS from known MTBSTFA reaction products that were previously observed in the pyrolysis EGA and GCMS experiments at Rocknest (21).

SAM EGA analyses of the JK blank and JK1, JK2, and JK3 samples demonstrated that the masses corresponding to the major MTBSTFA reaction products are reduced to background levels, as defined by QMS background scans of gases inside the pyrolysis oven and manifolds taken before the start of pyrolysis heating after boil-off 
(Fig. S3 and S4). These products and their most diagnostic ion fragments include contributions from: tert-butyldimethylsilanol (monosilylated $\mathrm{H}_{2} \mathrm{O}, \mathrm{MSW}, \mathrm{m} / z$, 75), 1,3bis(1,1-dimethylethyl)-1,1,3,3-tetramethyldisiloxane (bisilylated $\mathrm{H}_{2} \mathrm{O}, \mathrm{BSW}, \mathrm{m} / z, 147$ ), 2,2,2-trifluoro- $N$-methylacetamide (TFMA, m/z 127), and tert-butyldimethylfluorosilane (TBDMS-F, $m / z$ 134). These marker fragments were selected to minimize isobaric interferences from other volatiles, as the mass spectra for the above compounds overlap at numerous $\mathrm{m} / \mathrm{z}$ values. The total ion count for each compound was estimated based on integrated-peak counts for the marker fragment and then adjusted for ionization crosssection relative to $\mathrm{CO}_{2}$. The correlation between $\mathrm{O}_{2}$ release $\left({ }^{16} \mathrm{O}^{18} \mathrm{O}, \mathrm{m} / \mathrm{z} 34\right)$ and the sharp decrease in the intensities of the major MTBSTFA fragment ions and increase in chloromethane $\left(\mathrm{CH}_{3} \mathrm{Cl}, \mathrm{m} / \mathrm{z}\right.$ 52) and dichloromethane $\left(\mathrm{CH}_{2} \mathrm{Cl}_{2}, \mathrm{~m} / z\right.$ 84) observed in the JK3 analysis (see Fig. S3) provides evidence that some of these chlorinated hydrocarbons are forming during boil-off from a reaction of an oxychlorine compound in JK with organic C from MTBSTFA. A similar correlation was observed in the Rocknest EGA analyses $(10,21)$.

MTBSTFA reduction method used for the CB-5 sample: A different approach was used to reduce the background levels of MTBSTFA byproducts during pyrolysis for the SAM EGA analysis of the CB-5 sample. In the CB-5 EGA experiment, prior to the standard cup preconditioning sequence, the Sample Manipulation System (SMS) enclosure containing the sample cups was pumped out for $\sim 3$ hours by the SAM Wide Range Pump (WRP) while the SAM gas manifolds and transfer lines were heated to $\sim 135^{\circ} \mathrm{C}$. The empty cup was then preconditioned by being heated to $\sim 835^{\circ} \mathrm{C}$ while pumping through the heated manifold and gas lines and then the cup was allowed to cool while sealed inside the pyrolysis oven. Prior to removing the empty preconditioned cup from the pyrolysis oven, the cup was reheated to $\sim 120^{\circ} \mathrm{C}$ and then moved into position directly under the solid sample inlet tube to receive the CB-5 portion from CHIMRA. During the time the cup was outside of the pyrolysis oven, except for the sample drop, helium gas was used to flush the pyrolysis oven and SMS. After receiving the sample, the cup was sealed back inside the pyrolysis oven for the standard EGA-GC-TLS experiment. The total time the cup was exposed to the MTBSTFA vapor background inside the SMS during sample handoff was 13 minutes, roughly 5 minutes shorter than the sample handoff cup exposure time for the other single portion sample analyses of RN, JK, and CB. The SMS pump out, cup preheating, and reduced cup exposure time inside the SMS were designed to minimize the amount of MTBSTFA and DMF vapor believed to adsorb to both cup and sample surfaces during sample handoff (Fig. S5).

\section{Methods for GCMS Peak Identifications and Abundance Calculations:}

Identification of organic molecules detected by GCMS was based on mass spectral comparison (44) and comparison of relative retention times for standards. Absolute abundance calculations for each compound were based on integration of Gaussian fitted peaks (57) for the primary $\mathrm{m} / \mathrm{z}$ values of each compound. The total abundance of each identified peak was then estimated by calculating the sum of the areas from selected $\mathrm{m} / \mathrm{z}$ peak fits and comparing the total area to the peak areas from five separate hexane GCMS measurements that were conducted on the SAM instrument during pre-flight calibration (5). Hexane was used as a standard for the GCMS chlorinated hydrocarbon abundance calculations because this hydrocarbon was not identified in the SAM EGA or GCMS 
backgrounds and chlorinated hydrocarbon gas standards were not run on the SAM flight instrument during calibration. Differences in the relative molar response of hexane compared with the individual chlorinated hydrocarbons were accounted for in the abundance calculations using previously published experimental data for their electron ionization cross sections at 70 and $75 \mathrm{eV}$ (58-60). These GCMS abundances were also corrected for the gas fraction sent to the hydrocarbon trap during pyrolysis using EGA data (Table S2).

Fragments and reaction products associated with MTBSTFA, polysiloxanes derived from the GC column, hydrocarbon trap reaction and degradation products, as well as other volatiles known to be present in the SAM background were detected in both the blank and Rocknest GCMS analyses (Fig. S4). Sources of the SAM background volatiles are discussed in detail elsewhere (10). The peaks in the GCMS chromatograms in Fig. S4 are shown as the QMS intensity of the total ion current associated with several $\mathrm{m} / \mathrm{z}$ values as a function of GC retention time. No significant GCMS peak contributions were observed at higher masses $(\mathrm{m} / z>150)$ and therefore were not included in Fig. S4.

Methods for EGA Molar Abundance Calculations: Molar abundances shown in Table 1 were computed by the method described in Leshin et al. (10).

\section{Alpha Particle X-ray Spectrometer Additional Light Invisible Element Content:}

The basis for extraction of additional light invisible element content (ALIC) from APXS spectra is the intensity ratio between the L $\alpha$ Compton (C) and Rayleigh (R) scatter peaks. The method was calibrated using geochemical reference material spectra recorded on the flight-equivalent APXS instrument (61).

The spectrum fitting methodology has been described elsewhere (62). Because overlapping $\mathrm{Rb}$ and $\mathrm{Sr} \mathrm{X}$-ray peaks reduce the accuracy of $\mathrm{C} / \mathrm{R}$ determination, the GRMs used here were limited to those containing less than $500 \mathrm{ppm}$ of these two elements. A Monte Carlo simulation code was employed to predict the $\mathrm{C} / \mathrm{R}$ values that would be expected on the basis of the known element concentrations in the GRMs. The ratio $K$ between the simulated and measured $\mathrm{C} / \mathrm{R}$ ratios should in principle be unity. In practice it is approximately 0.9 , which probably reflects residual inaccuracy in theoretical scattering cross-sections at the very low X-ray energies involved here. Fig. S6 shows the dependence of $K$ upon the known concentration fraction $\mathrm{F}(\mathrm{I})$ of all elements having atomic number below 11. These elements do not contribute characteristic X-rays to the spectra; $\mathrm{F}(\mathrm{I})$ is dominated by cation-bound oxygen, and has further contributions from $\mathrm{H}_{2} \mathrm{O}, \mathrm{CO}_{2}, \mathrm{~F}, \mathrm{Li}_{2} \mathrm{O}$. An error-weighted least-squares fit gives $\mathrm{K}=0.951-0.14 \mathrm{~F}(\mathrm{I})$.

The JK and CB spectra were each recorded in 20-minute time segments over an $\sim 4$ hour time period starting late in the evening. Over the entire duration of each measurement, the ambient temperature changed monotonically and consequently the $\mathrm{X}$ ray detector resolution varied. Only those segments with excellent energy resolution ( $150 \mathrm{eV} \mathrm{FWHM}$ at $5.9 \mathrm{keV}$ ) were summed to provide spectra for fitting. The $\mathrm{C} / \mathrm{R}$ ratios from spectrum fitting are in Table S3. 
The $\mathrm{C} / \mathrm{R}$ ratios were also simulated using the GUAPX concentrations (61). Obviously, these concentrations exclude any ALIC component, and so the simulations were repeated with added $\mathrm{H}_{2} \mathrm{O}$ in $5 \mathrm{wt} \%$ increments. Table $\mathrm{S} 3$ lists the simulated $\mathrm{C} / \mathrm{R}$ values, and the resulting $\mathrm{K}$-values that correspond to each $\mathrm{H}_{2} \mathrm{O}$ value. $\mathrm{K}$ increases linearly with added $\mathrm{H}_{2} \mathrm{O}$ content. The intersection between the calibration $\mathrm{K}-\mathrm{F}(\mathrm{I})$ line and the sample K-ALIC wt\% relationship gives the weight fraction of ALICs in the sample. The calculated ALICs for both JK and CB are summarized in Table S3.

SAM Analog Samples: Mars analog samples were analyzed by laboratory thermal analyzers integrated with quadrupole mass spectrometers under operating conditions similar to SAM $(31,63,64)$ and the Thermal Evolved Gas Analyzer (TEGA) onboard the Mars Phoenix lander mission $(24,65)$. Montmorillonite (SWy-1, Clay Mineral Society Source Clays Repository) and nontronite (SWa-1, Clay Mineral Society Source Clays Repository) shown in Figure 3a were run under TEGA-like operating conditions (100 $\mathrm{mb}, \mathrm{N}_{2}$ carrier gas, $20^{\circ} \mathrm{C} / \mathrm{min}$ temperature ramp rate). Fe-saponite (Griffithite, Hollywood, CA) was run under SAM-like operating conditions (30 mb, He carrier gas, $35^{\circ} \mathrm{C} /$ min temperature ramp rate). Evolved $\mathrm{O}_{2}, \mathrm{SO}_{2}, \mathrm{HCl}$, and $\mathrm{H}_{2} \mathrm{~S}$ for pyrrhotite (Santa Eulalia, Chihuahua, Mexico) mixed with Ca-perchlorate (reagent grade) shown in Fig. 3b were run under SAM-like operating conditions. Akaganeite and calcite evolved gas analysis shown in Fig. S2 were run under SAM-like operating conditions. Runs include a synthetic akaganeite mixed with Iceland spar calcite, synthetic akaganeite only, and Iceland spar calcite only. The experimental methods used for the akaganeite and pyrrhotite runs are the same as those described in Sutter et al. (64). Evolved $\mathrm{O}_{2}$ from the thermal decomposition of perchlorate salts shown in Fig. 3c were also run under SAMlike operating conditions, with the exception of K-perchlorate that was run at $12 \mathrm{mbar}$ pressure with a $\mathrm{N}_{2}$ flow gas. Materials and methods for these experiments are presented in Sutter et al. (64). 

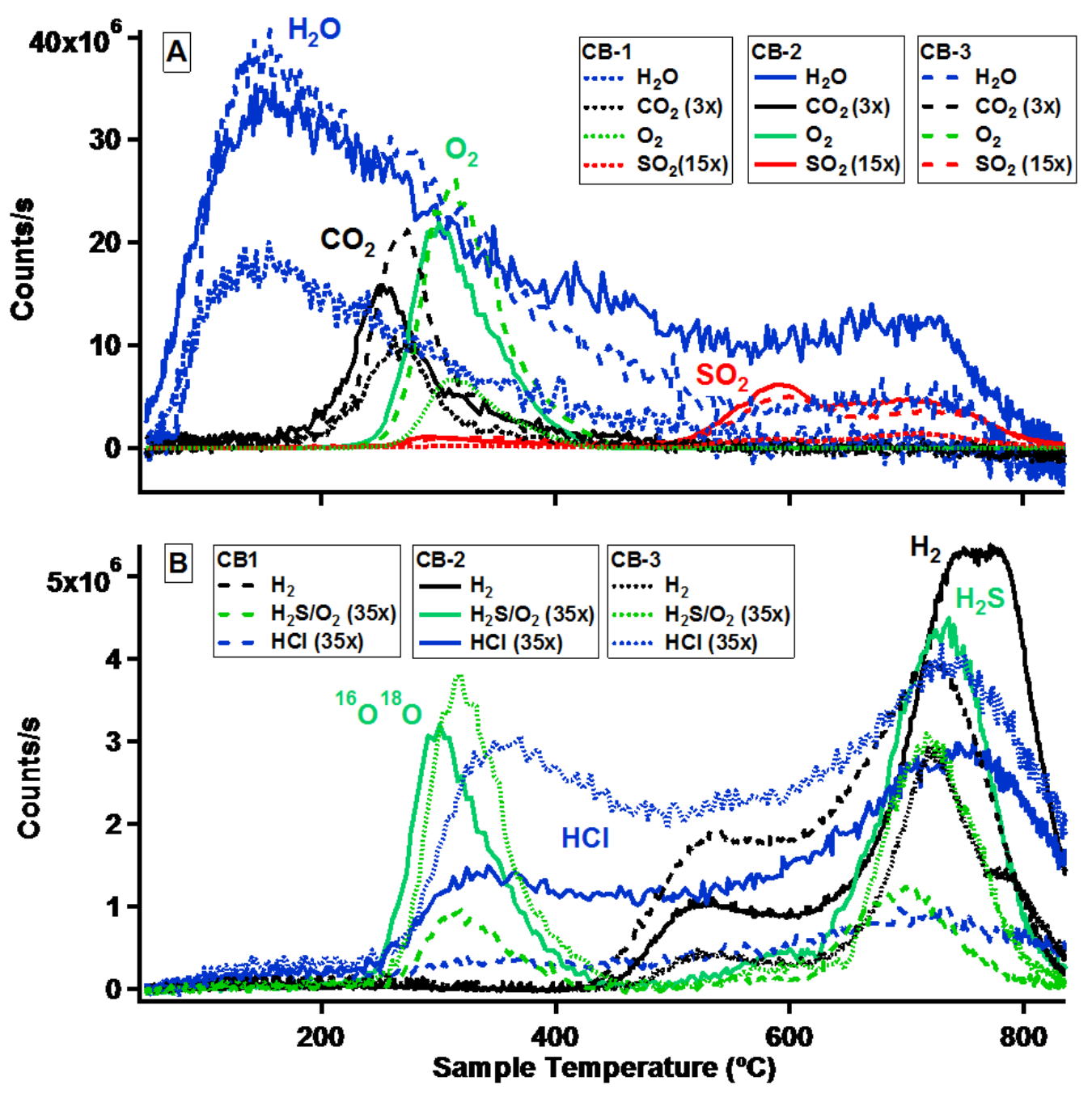

Fig. S1. Comparison of evolved gases for continuous temperature ramps of Cumberland samples (CB-1, CB-2, and CB-3) run in SAM [Note. CB-5 is not plotted here because of a different sample cup pretreatment. See section "MTBSTFA reduction method for CB-5 sample" above for details of CB5]. Pyrolysis of the three samples resulted in similar evolved gas traces; although there were small differences in abundance between the three runs (see Table 1 for abundances). A) Most-abundant evolved gases $\left[\mathrm{CO}_{2}, \mathrm{O}_{2}\right.$, and $\mathrm{SO}_{2}$ counts have been scaled up 3, 15, and 15 times, respectively]. B) Evolved gas traces for $\mathrm{H}_{2}(\mathrm{~m} / \mathrm{z} 2), \mathrm{H}_{2} \mathrm{~S}(\mathrm{~m} / \mathrm{z} 34)$, and $\mathrm{HCl}(\mathrm{m} / \mathrm{z} \mathrm{36})\left[\mathrm{H}_{2} \mathrm{~S}\right.$ and $\mathrm{HCl}$ traces have been scaled 35 times]. The $\mathrm{m} / \mathrm{z} 34$ peak at $\sim 300{ }^{\circ} \mathrm{C}$ is due to ${ }^{16} \mathrm{O}^{18} \mathrm{O}$ that masks the $\mathrm{H}_{2} \mathrm{~S}$ release in this temperature region. Isotopologues were used to estimate species that saturated the QMS detector $\left(\mathrm{m} / \mathrm{z} 12\right.$ for $\mathrm{CO}_{2}$ and $\mathrm{m} / \mathrm{z} 20$ for $\left.\mathrm{H}_{2} \mathrm{O}\right)$. 


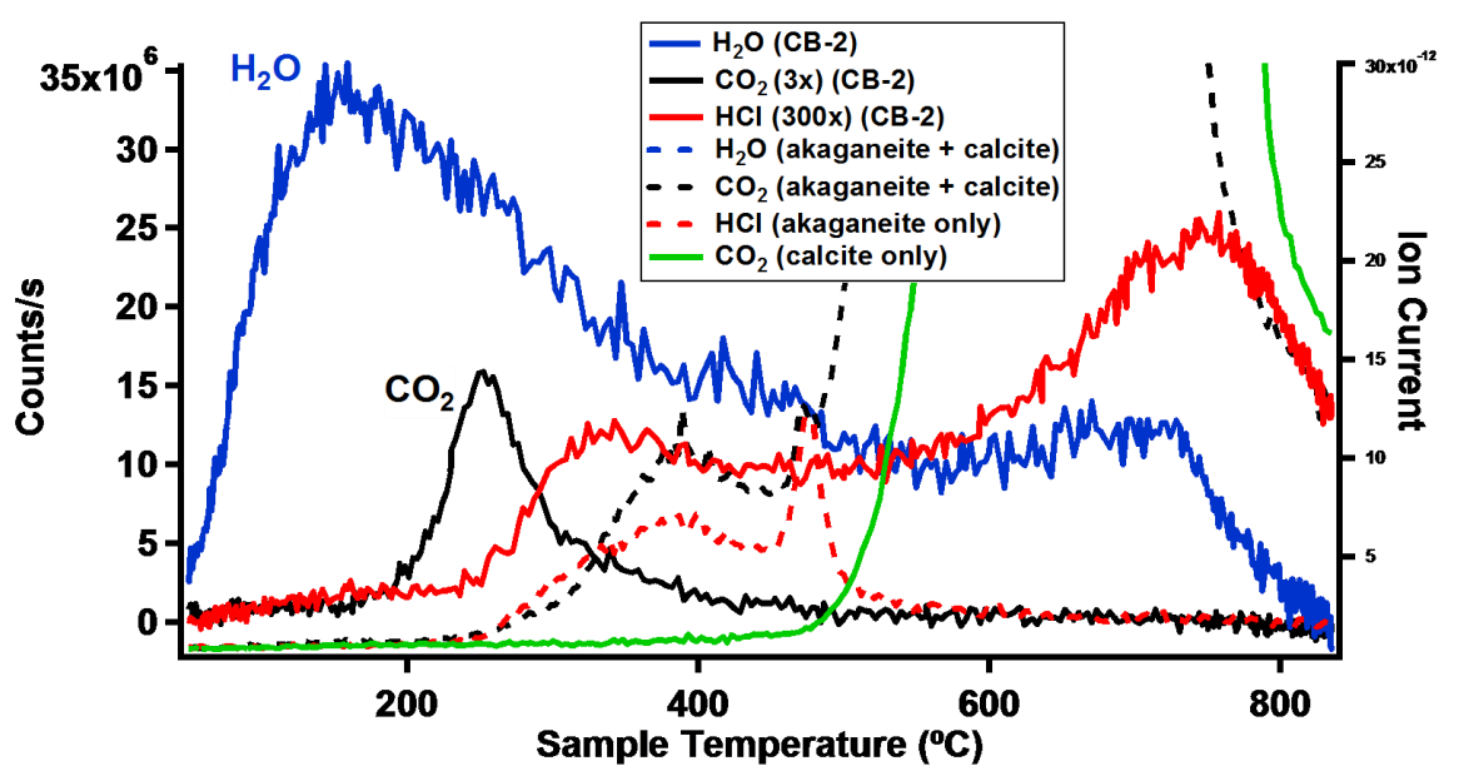

Fig. S2. Evolved $\mathrm{H}_{2} \mathrm{O}, \mathrm{CO}_{2}$, and $\mathrm{HCl}$ for the second run of the Cumberland (CB-2) drilled material and laboratory evolved gas analysis of akaganeite, calcite, and a mixture of akaganeite + calcite. The evolution of $\mathrm{HCl}$ from akaganeite thermal decomposition results in acidic dissolution and subsequent thermal decomposition of some calcite thereby lowering the temperature of $\mathrm{CO}_{2}$ release in the akaganeite + calcite sample compared with calcite only. A similar process of acidic dissolution and subsequent thermal decomposition of carbonates is a candidate for the $\mathrm{CO}_{2}$ release in $\mathrm{CB}$. 


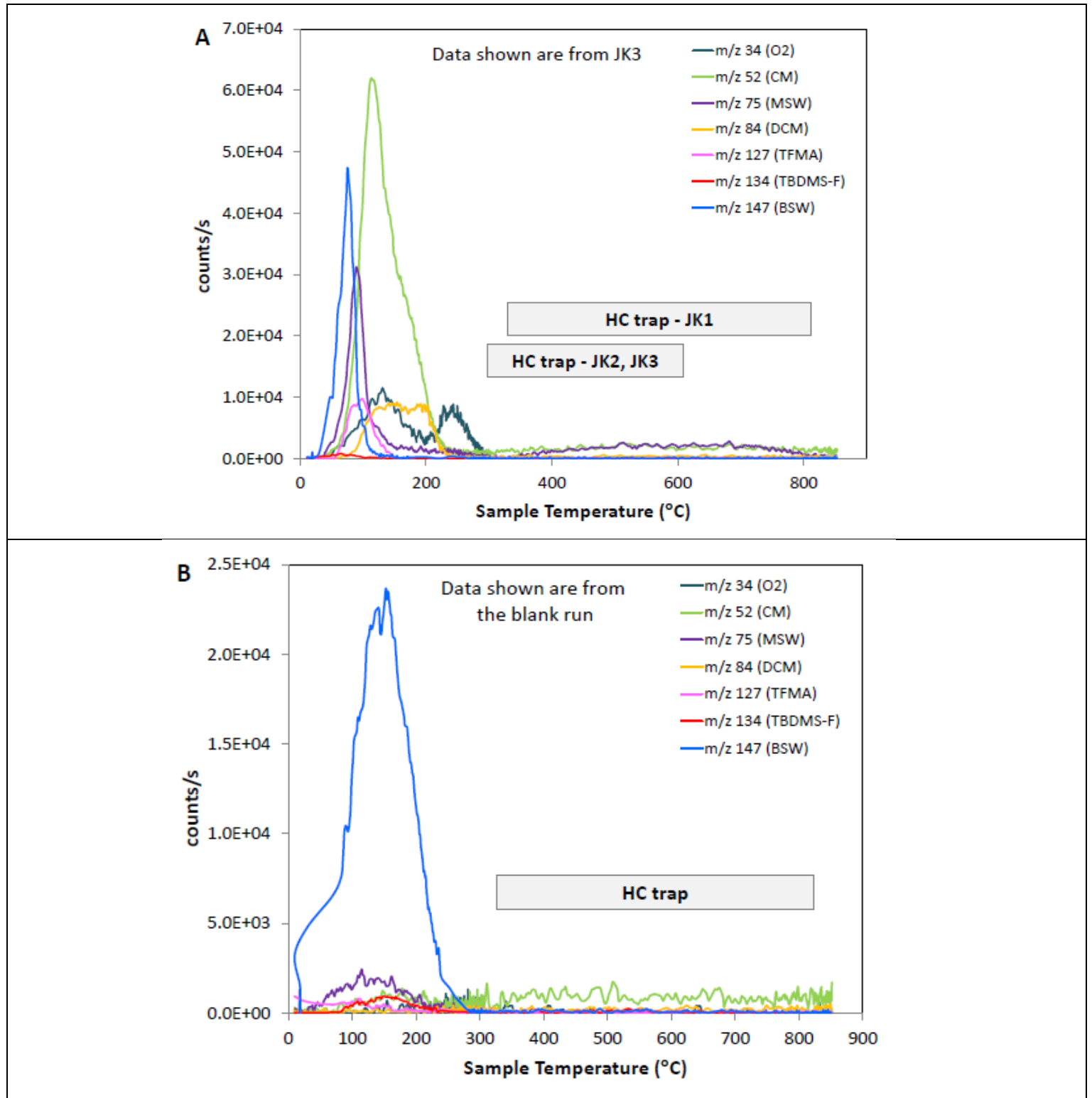

Fig. S3. (A) SAM evolved gas analysis of John Klein (JK-3) compared with the empty cup blank run (B) showing selected $\mathrm{m} / \mathrm{z}$ values plotted in counts per second as a function of sample temperature during the pyrolysis run. The ions utilized to quantify several key compounds, with $m / z$ values noted in the legend: $\mathrm{O}_{2}\left({ }^{16} \mathrm{O}^{18} \mathrm{O}, \mathrm{m} / z\right.$ 34), chloromethane $(\mathrm{CM}, \mathrm{m} / z, 52)$, dichloromethane (DCM, $m / z, 84)$, tert-butyldimethylsilanol or monosilylated water (MSW, $m / z$ 75), 1,3-bis(1,1-dimethylethyl)-1,1,3,3-tetramethyldisiloxane or bisilylated water (BSW, $\mathrm{m} / \mathrm{z}$ 147), tert-butyldimethylfluorosilane (TDBMS$\mathrm{F}, m / z, 134$ ), and 2,2,2-trifluoro-N-methyl-acetamide (TFMA, $m / z$ 127). The hydrocarbon trap (HC trap) temperature cut for the GC analyses is indicated by the shaded bar. 


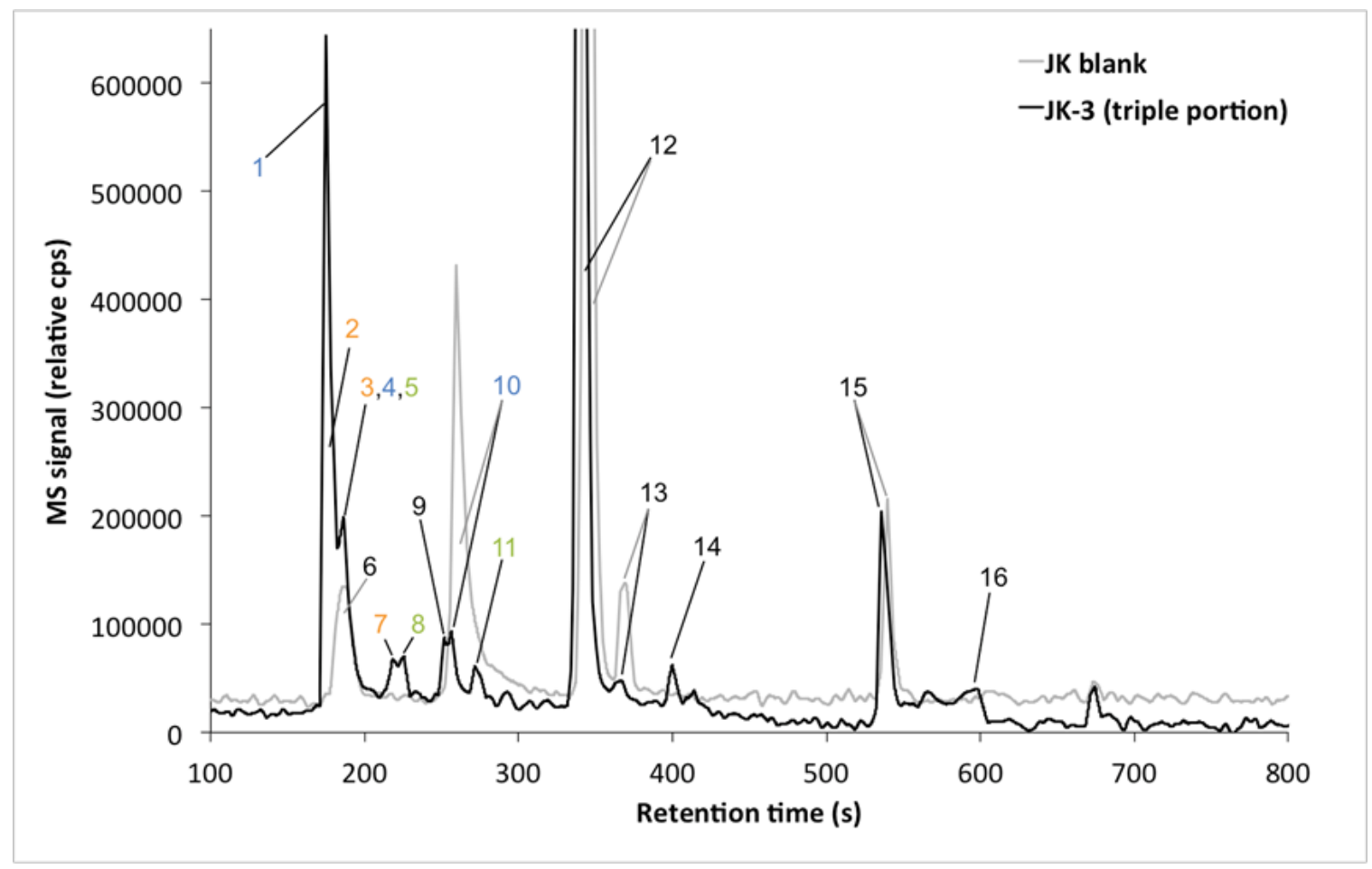

Fig. S4. Comparison of gas chromatograms from the John Klein (JK) empty cup blank (gray) and the JK-3 run consisting of a cup with a triple portion of sample (black) showing peaks of identified compounds and their retention times. The chromatograms are the sum of specific ion masses. The signal for some ion chromatograms was enhanced using multiplication factors as stated, applied equally to the blank and JK-3 sample data. Blue numbered peaks are $\mathrm{N}$-containing compounds, orange numbered peaks are $\mathrm{S}$ containing compounds, and green numbered peaks are oxychlorine compounds. The numbered peaks correspond to the following identifications, ions and multiplication factors used in generating chromatograms: 1 : nitric oxide, $m / z, 30 ; 2$ : hydrogen sulfide, $\mathrm{m} / \mathrm{z}$ 35; 3: carbonyl sulfide, $\mathrm{m} / \mathrm{z}, 60 ; 4$ : hydrogen cyanide, $\mathrm{m} / \mathrm{z}, 27 ; 5$ : chloromethane, $\mathrm{m} / \mathrm{z}$ 52; 6: 2-methylpropene, $\mathrm{m} / \mathrm{z} 41 ; 7$ : carbon disulfide, $\mathrm{m} / \mathrm{z}$ 76; 8: dichloromethane, $\mathrm{m} / \mathrm{z} 86$ (6x); 9: acetone, $m / z 58(2 x)$; 10: acetonitrile, $m / z$ 41; 11 : trichloromethane, $m / z ~ 83 ; 12$ : benzene, $m / z$ 78; 13: tert-butyldimethylfluorosilane (TBDMS-F), $m / z$ 56; $14: 2,4,4$ trimethylpentene, $m / z, 41 ; 15$ : toluene, $m / z 56+m / z$ 91; 16 : column bleeding, $m / z, 207$ (2x). Peaks $1,2,3,4,5,7,8,9,14$ and 16 are substantially more abundant in the samplederived volatiles than in the blank. Peaks 6,10 and 13 are attributed to MTBSTFA degradation products and are substantially more abundant in the blank than in the sample, suggesting additional degradation of MTBSTFA products when heated in the presence of solid sample. With the exception of TBDMS-F, none of the other major MTBSTFA byproducts (MSW, BSW, and TFMA) were observed in the runs at a significant level due to the initial boil-off and the high-temperature cut of evolved gas sent to the GCMS. 


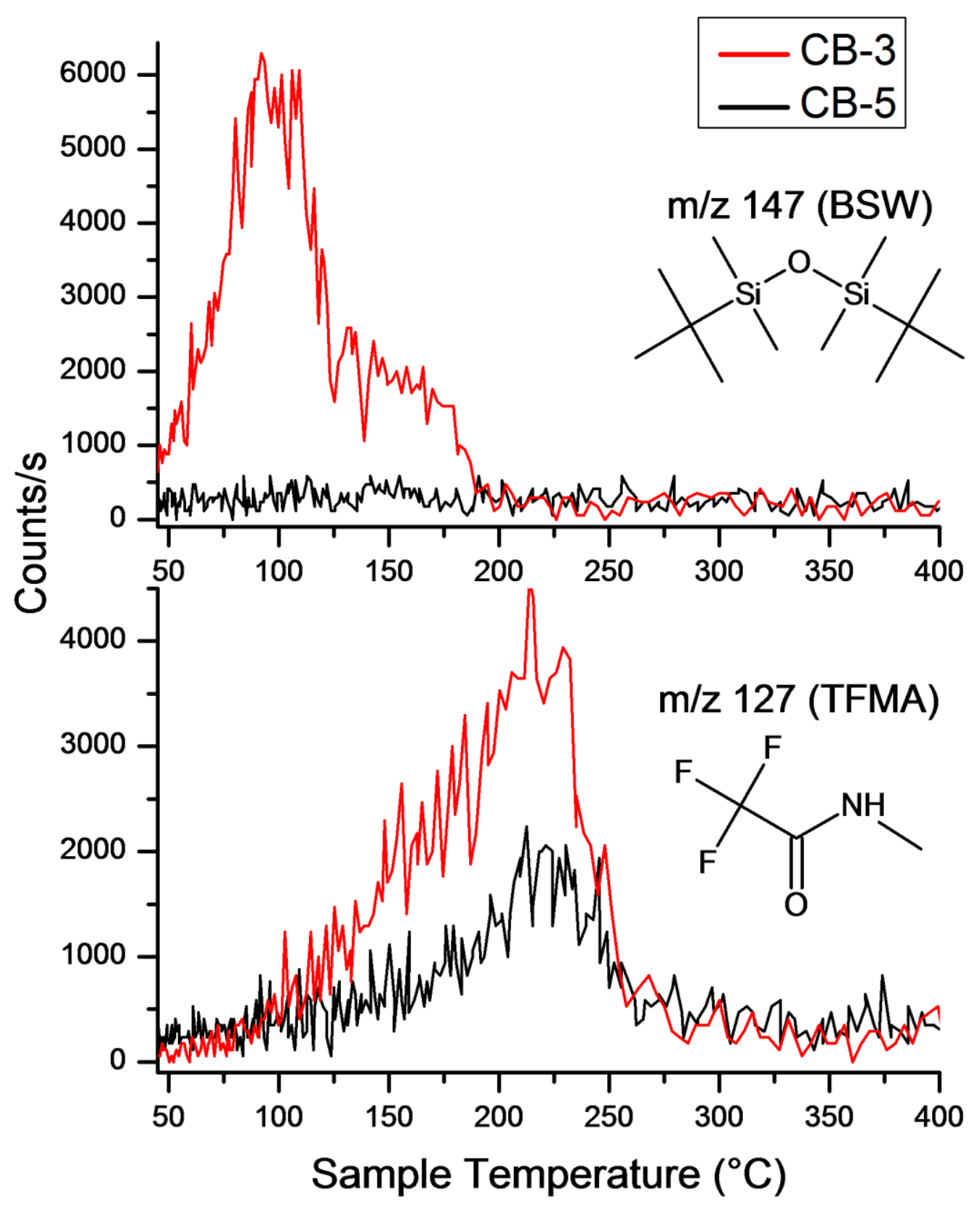

Fig. S5. Evolved gas analyses of $N$-methyl- $N$-(tert-butyldimethylsilyl)

trifluoroacetamide (MTBSTFA) hydrolysis products in Cumberland (CB) CB-3 and CB5 samples. 1,3-bis(1,1-dimethylethyl)-1,1,3,3-tetramethyldisiloxane $(\mathrm{m} / \mathrm{z} 147)$ from CB5 is compared with CB-3 in the top figure. The absence of 1,3-bis(1,1-dimethylethyl)1,1,3,3-tetramethyldisiloxane in CB-5 is due to cup preheating to $120{ }^{\circ} \mathrm{C}$ to reduce the amount of MTBSTFA prior to delivery of sample to the cup [See section "MTBSTFA reduction method for CB-5 sample" above for details of CB5 pretreatment]. N-methyl2,2,2-trifluoroacetamide $(\mathrm{m} / \mathrm{z}, 127)$ in CB-5 is also reduced compared with CB-3, shown in the bottom figure. 


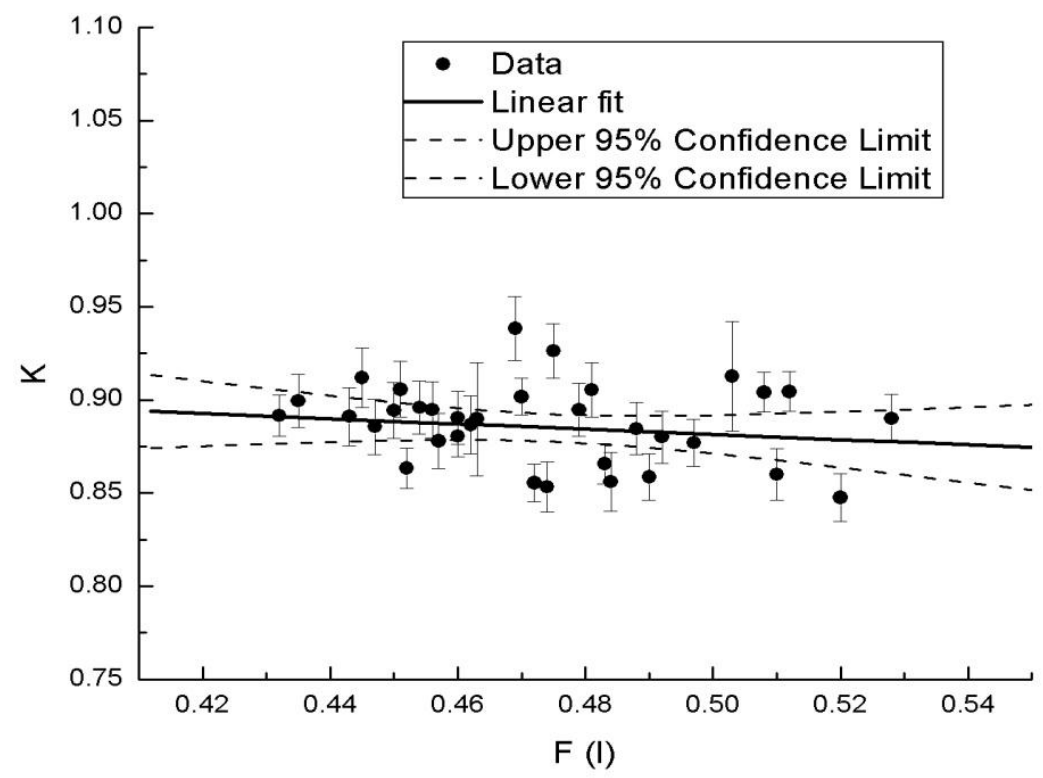

Fig. S6. Calibration of the K-ratio method using geochemical reference materials. 
Table S1. Details of the SAM evolved gas analysis (EGA) and gas chromatography mass spectroscopy (GCMS) experiments conducted on empty cup blanks and samples from the John Klein and Cumberland drill holes.

\begin{tabular}{|c|c|c|c|c|}
\hline $\begin{array}{l}\text { Drill Hole } \\
\text { Target }\end{array}$ & $\begin{array}{l}\text { Sample } \\
\text { Number }\end{array}$ & $\begin{array}{l}\text { Analysis } \\
\text { on Mars } \\
\text { (Sol \#) }\end{array}$ & $\begin{array}{l}\text { EGA Pyrolysis } \\
\text { Temperature" }\end{array}$ & $\begin{array}{l}\text { GC Hydrocarbon } \\
\text { Trap Cut }^{\dagger}\end{array}$ \\
\hline \multirow{5}{*}{$\begin{array}{c}\text { John Klein } \\
\qquad(\text { JK) }\end{array}$} & JK Blank & 177 & $\begin{array}{l}\text { Boil-off to } 218^{\circ} \mathrm{C} \text {; temp. } \\
\text { ramp: } 217-864^{\circ} \mathrm{C}\end{array}$ & $314-822^{\circ} \mathrm{C}$ \\
\hline & JK-1 & 196 & $\begin{array}{l}\text { Boil-off to } 218^{\circ} \mathrm{C} \text {; temp. } \\
\text { ramp: } 218-866^{\circ} \mathrm{C}\end{array}$ & $314-822^{\circ} \mathrm{C}$ \\
\hline & JK-2 & 199 & $\begin{array}{l}\text { Boil-off to } 218^{\circ} \mathrm{C} \text {; temp. } \\
\text { ramp: } 218-865^{\circ} \mathrm{C}\end{array}$ & $245-643^{\circ} \mathrm{C}$ \\
\hline & $\begin{array}{l}\text { JK-3 } \\
\text { (3x portion) }\end{array}$ & 224 & $\begin{array}{l}\text { Boil-off; to } 218^{\circ} \mathrm{C} \text { temp. } \\
\text { ramp: } 218-864^{\circ} \mathrm{C}\end{array}$ & $245-643^{\circ} \mathrm{C}$ \\
\hline & JK-4 & 227 & $\begin{array}{l}\text { Continuous temp. ramp } \\
34-835^{\circ} \mathrm{C}\end{array}$ & $574-797^{\circ} \mathrm{C}$ \\
\hline \multirow{5}{*}{$\begin{array}{c}\text { Cumberland } \\
(\text { CB })^{\S}\end{array}$} & $\begin{array}{l}\text { CB } \\
\text { Blank }\end{array}$ & 277 & $\begin{array}{l}\text { Continuous temp. ramp } \\
34-835^{\circ} \mathrm{C}\end{array}$ & $445-548^{\circ} \mathrm{C}$ \\
\hline & CB-1 & 282 & $\begin{array}{l}\text { Continuous temp. ramp } \\
34-835^{\circ} \mathrm{C}\end{array}$ & $445-548^{\circ} \mathrm{C}$ \\
\hline & CB-2 & 286 & $\begin{array}{l}\text { Continuous temp. ramp } \\
34-835^{\circ} \mathrm{C}\end{array}$ & $574-797^{\circ} \mathrm{C}$ \\
\hline & CB-3 & 290 & $\begin{array}{l}\text { Continuous temp. ramp } \\
34-835^{\circ} \mathrm{C}\end{array}$ & $229-350^{\circ} \mathrm{C}$ \\
\hline & CB-5 & 368 & $\begin{array}{l}\text { MTBSTFA/DMF } \\
\text { reduction }{ }^{* *} \text {; Continuous } \\
\text { temp. ramp } \\
34-846^{\circ} \mathrm{C}\end{array}$ & $229-350^{\circ} \mathrm{C}$ \\
\hline
\end{tabular}

*Estimated cup temperature calculated from the SAM pyrolysis oven 1 heater wire temperature data during the pyrolysis ramp using temperature models and a polynomial fit based on pre-launch testing.

${ }^{\dagger}$ Gas chromatography (GC) hydrocarbon trap cut refers to the temperature range over which volatiles were collected on the hydrocarbon trap during pyrolysis for GCMS analyses.

${ }^{\S}$ The details for CB-4 were not included since this experiment was an EGA noble gas enrichment experiment that is not discussed in this paper.

**The MTBSTFA/DMF reduction experiment used in the analysis of CB-5 included a pump-out of the Sample Manipulation System (SMS) and preheating of the sample cup in the pyrolysis oven to $\sim 120^{\circ} \mathrm{C}$ prior to receiving the sample from Curiosity's sample delivery system. 
Table S2. Chlorinated hydrocarbon abundances measured by SAM gas chromatography mass spectroscopy (GCMS).

\begin{tabular}{|c|c|c|c|c|c|}
\hline & $\begin{array}{l}\text { GC Temp } \\
\text { Cut }\left({ }^{\circ} \mathbf{C}\right)\end{array}$ & $\begin{array}{l}\mathrm{CH}_{3} \mathrm{Cl} \\
(\mathrm{nmol})\end{array}$ & $\begin{array}{c}\mathrm{CH}_{2} \mathrm{Cl}_{2} \\
(\mathrm{nmol})\end{array}$ & $\begin{array}{l}\mathrm{CHCl}_{3} \\
\text { (nmol) }\end{array}$ & $\begin{array}{c}\mathrm{CCl}_{4} \\
(\mathrm{nmol})\end{array}$ \\
\hline $\begin{array}{c}\mathrm{m} / z \text { values } \\
\text { used for } \\
\text { abundances }{ }^{\dagger}\end{array}$ & & $\begin{array}{c}13,15,35,47,49 \\
50,51, \underline{\mathbf{2}}\end{array}$ & $\begin{array}{c}35,41,47,49,51 \\
\underline{\mathbf{8 4}}, 86,88\end{array}$ & $\begin{array}{c}35,47,82,8 \mathbf{8 3}, 84 \\
85,87\end{array}$ & $\begin{array}{c}35,37,47,49,82,84, \mathbf{1 1 7} \\
119,121,123\end{array}$ \\
\hline JK Blank & $314-822$ & $0.15 \pm 0.06$ & $<0.002$ & $<0.001$ & $<0.001$ \\
\hline JK-1 & $314-822$ & $0.59 \pm 0.22$ & $0.02 \pm 0.01$ & $<0.001$ & $<0.001$ \\
\hline JK-2 & $245-643$ & $0.40 \pm 0.15$ & $0.03 \pm 0.01$ & $<0.001$ & $<0.001$ \\
\hline $\begin{array}{l}\text { JK-3 } \\
\text { (3x portion) }\end{array}$ & $245-643$ & $0.86 \pm 0.32$ & $0.06 \pm 0.02$ & $0.015 \pm 0.006$ & $0.003 \pm 0.001$ \\
\hline JK-4 & $574-797$ & $0.49 \pm 0.18$ & $0.005 \pm 0.002$ & $<0.001$ & $<0.002$ \\
\hline CB Blank & $445-545$ & $2.8 \pm 1.0^{*}$ & $<0.09^{*}$ & $<0.003$ & $<0.001$ \\
\hline CB-1 & $445-545$ & $6.5 \pm 2.4^{\ddagger}$ & $0.20 \pm 0.07^{*}$ & $<0.001$ & $<0.001$ \\
\hline CB-2 & $574-797$ & $0.33 \pm 0.12$ & $0.009 \pm 0.003$ & $<0.001$ & $<0.001$ \\
\hline CB-3 & $229-350$ & $4.7 \pm 1.8$ & $2.4 \pm 0.9^{*}$ & $0.045 \pm 0.017^{*}$ & $0.012 \pm 0.004$ \\
\hline CB-5 & $229-350$ & $1.8 \pm 0.7^{\ddagger}$ & $1.1 \pm 0.4^{*}$ & $0.035 \pm 0.013^{*}$ & $0.009 \pm 0.003^{\ddagger}$ \\
\hline
\end{tabular}

*Calculated abundances $\left(10^{-9} \mathrm{~mol}\right)$ of chloromethane $\left(\mathrm{CH}_{3} \mathrm{Cl}\right)$, dichloromethane $\left(\mathrm{CH}_{2} \mathrm{Cl}_{2}\right)$, trichloromethane $\left(\mathrm{CHCl}_{3}\right)$, and carbon tetrachloride $\left(\mathrm{CCl}_{4}\right)$ measured in the empty cup blanks, John Klein (JK1-4), and Cumberland (CB1-3, and CB-5). Data for CB-4 is not included since there was no $\mathrm{GC}$ analysis during this experiment.

${ }^{\dagger}$ In order to minimize $\mathrm{m} / \mathrm{z}$ contributions from other compounds in the GCMS data, the abundances of the chlorinated hydrocarbons were determined from the total peak area calculated from the sum of selected masses determined from a Gaussian fitted peak area of the underlined $\mathrm{m} / \mathrm{z}$ values and assuming relative $\mathrm{m} / \mathrm{z}$ intensities for the other masses listed determined from NIST. Errors ( $1 \sigma$ standard deviation) are based on the average value determined from five individual hexane measurements made during pre-flight calibration of SAM.

Values corrected for the fraction of gas sent to the hydrocarbon trap during the pyrolysis experiment for GCMS analysis based on the specific hydrocarbon trap cut temperature range. 
Table S3. Summary of simulated and experimental Compton/Rayleigh (C/R), K-values (K), and additional light invisible element content (ALIC) wt. \% values for the APXS targets John Klein (spot 7, sol 230) and Cumberland (sol 287).

\begin{tabular}{ccccc}
\hline & $\begin{array}{c}\text { John Klein (spot 7) } \\
\text { (sol 230) }\end{array}$ & $\begin{array}{c}\text { Error } \\
\mathbf{( 2 \sigma )}\end{array}$ & $\begin{array}{c}\text { Cumberland } \\
\text { (sol 287) }\end{array}$ & $\begin{array}{c}\text { Error } \\
\mathbf{( 2 \sigma )}\end{array}$ \\
\hline Experimental C/R & 1.70 & 0.06 & 1.765 & 0.06 \\
Sim C/R (0\% ALICs) & 1.457 & 0.005 & 1.479 & 0.007 \\
Sim C/R (5\% ALICs) & 1.517 & 0.006 & 1.533 & 0.007 \\
Sim C/R (10\% ALICs) & 1.594 & 0.006 & 1.610 & 0.008 \\
Sim C/R (15\% ALICs) & N/A & N/A & 1.673 & 0.008 \\
K (0\% ALICs) & 0.86 & 0.03 & 0.84 & 0.03 \\
K (5\% ALICs) & 0.89 & 0.03 & 0.87 & 0.03 \\
K (10\% ALICs) & 0.94 & 0.03 & 0.91 & 0.03 \\
K (15\% ALICs) & N/A & N/A & 0.95 & 0.03 \\
ALIC wt\% & 4.3 & 5.5 & 6.9 & 5.8 \\
\hline
\end{tabular}


MSL Science Team Author List

Aalto University

Osku Kemppinen

Applied Physics Laboratory (APL) at Johns Hopkins University

Nathan Bridges, Jeffrey R. Johnson, Michelle Minitti

Applied Research Associates, Inc. (ARA)

David Cremers

Arizona State University (ASU)

James F. Bell III, Lauren Edgar, Jack Farmer, Austin Godber, Meenakshi Wadhwa,

Danika Wellington

Ashima Research

Ian McEwan, Claire Newman, Mark Richardson

ATOS Origin

Antoine Charpentier, Laurent Peret

Australian National University (ANU)

Penelope King

Bay Area Environmental Research Institute (BAER)

Jennifer Blank

Big Head Endian LLC

Gerald Weigle

Brock University

Mariek Schmidt

Brown University

Shuai Li, Ralph Milliken, Kevin Robertson, Vivian Sun

California Institute of Technology (Caltech)

Michael Baker, Christopher Edwards, Bethany Ehlmann, Kenneth Farley, Jennifer

Griffes, John Grotzinger, Hayden Miller, Megan Newcombe, Cedric Pilorget, Melissa

Rice, Kirsten Siebach, Katie Stack, Edward Stolper

Canadian Space Agency (CSA)

Claude Brunet, Victoria Hipkin, Richard Léveillé, Geneviève Marchand, Pablo Sobrón Sánchez

\section{Capgemini France}


Laurent Favot

\section{Carnegie Institution of Washington}

George Cody, Andrew Steele

Carnegie Mellon University

Lorenzo Flückiger, David Lees, Ara Nefian

Catholic University of America

Mildred Martin

Centre National de la Recherche Scientifique (CNRS)

Marc Gailhanou, Frances Westall, Guy Israël

Centre National d'Etudes Spatiales (CNES)

Christophe Agard, Julien Baroukh, Christophe Donny, Alain Gaboriaud, Philippe

Guillemot, Vivian Lafaille, Eric Lorigny, Alexis Paillet, René Pérez, Muriel Saccoccio, Charles Yana

\section{Centro de Astrobiología (CAB)}

Carlos Armiens-Aparicio, Javier Caride Rodríguez, Isaías Carrasco Blázquez, Felipe Gómez Gómez , Javier Gómez-Elvira, Sebastian Hettrich, Alain Lepinette Malvitte, Mercedes Marín Jiménez, Jesús Martínez-Frías, Javier Martín-Soler, F. Javier MartínTorres, Antonio Molina Jurado, Luis Mora-Sotomayor, Guillermo Muñoz Caro, Sara Navarro López, Verónica Peinado-González, Jorge Pla-García, José Antonio Rodriguez Manfredi, Julio José Romeral-Planelló, Sara Alejandra Sans Fuentes, Eduardo Sebastian Martinez, Josefina Torres Redondo, Roser Urqui-O'Callaghan, María-Paz Zorzano Mier

\section{Chesapeake Energy}

Steve Chipera

Commissariat à l'Énergie Atomique et aux Énergies Alternatives (CEA)

Jean-Luc Lacour, Patrick Mauchien, Jean-Baptiste Sirven

\section{Concordia College}

Heidi Manning

\section{Cornell University}

Alberto Fairén, Alexander Hayes, Jonathan Joseph, Steven Squyres, Robert Sullivan, Peter Thomas

\section{CS Systemes d'Information}

Audrey Dupont

Delaware State University

Angela Lundberg, Noureddine Melikechi, Alissa Mezzacappa 
Denver Museum of Nature \& Science

Julia DeMarines, David Grinspoon

Deutsches Zentrum für Luft- und Raumfahrt (DLR)

Günther Reitz

eINFORMe Inc. (at NASA GSFC)

Benito Prats

Finnish Meteorological Institute

Evgeny Atlaskin, Maria Genzer, Ari-Matti Harri, Harri Haukka, Henrik Kahanpää, Janne

Kauhanen, Osku Kemppinen, Mark Paton, Jouni Polkko, Walter Schmidt, Tero Siili

GeoRessources

Cécile Fabre

Georgia Institute of Technology

James Wray, Mary Beth Wilhelm

Géosciences Environnement Toulouse (GET)

Franck Poitrasson

Global Science \& Technology, Inc.

Kiran Patel

Honeybee Robotics

Stephen Gorevan, Stephen Indyk, Gale Paulsen

Imperial College

Sanjeev Gupta

Indiana University Bloomington

David Bish, Juergen Schieber

Institut d'Astrophysique Spatiale (IAS)

Brigitte Gondet, Yves Langevin

Institut de Chimie des Milieux et Matériaux de Poitiers (IC2MP)

Claude Geffroy

Institut de Recherche en Astrophysique et Planétologie (IRAP), Université de Toulouse 
David Baratoux, Gilles Berger, Alain Cros, Claude d'Uston, Olivier Forni, Olivier Gasnault, Jérémie Lasue, Qiu-Mei Lee, Sylvestre Maurice, Pierre-Yves Meslin, Etienne Pallier, Yann Parot, Patrick Pinet, Susanne Schröder, Mike Toplis

Institut des Sciences de la Terre (ISTerre)

Éric Lewin

inXitu

Will Brunner

Jackson State University

Ezat Heydari

Jacobs Technology

Cherie Achilles, Dorothy Oehler, Brad Sutter

Laboratoire Atmosphères, Milieux, Observations Spatiales (LATMOS)

Michel Cabane, David Coscia, Guy Israël, Cyril Szopa

Laboratoire de Géologié de Lyon : Terre, Planète, Environnement (LGL-TPE)

Gilles Dromart

Laboratoire de Minéralogie et Cosmochimie du Muséum (LMCM)

François Robert, Violaine Sautter

Laboratoire de Planétologie et Géodynamique de Nantes (LPGN)

Stéphane Le Mouélic, Nicolas Mangold, Marion Nachon

Laboratoire Génie des Procédés et Matériaux (LGPM)

Arnaud Buch

Laboratoire Interuniversitaire des Systèmes Atmosphériques (LISA)

Fabien Stalport, Patrice Coll, Pascaline François, François Raulin, Samuel Teinturier

Lightstorm Entertainment Inc.

James Cameron

Los Alamos National Lab (LANL)

Sam Clegg, Agnès Cousin, Dorothea DeLapp, Robert Dingler, Ryan Steele Jackson, Stephen Johnstone, Nina Lanza, Cynthia Little, Tony Nelson, Roger C. Wiens, Richard B. Williams

Lunar and Planetary Institute (LPI)

Andrea Jones, Laurel Kirkland, Allan Treiman 
Malin Space Science Systems (MSSS)

Burt Baker, Bruce Cantor, Michael Caplinger, Scott Davis, Brian Duston, Kenneth Edgett, Donald Fay, Craig Hardgrove, David Harker, Paul Herrera, Elsa Jensen, Megan R. Kennedy, Gillian Krezoski, Daniel Krysak, Leslie Lipkaman, Michael Malin, Elaina McCartney, Sean McNair, Brian Nixon, Liliya Posiolova, Michael Ravine, Andrew Salamon, Lee Saper, Kevin Stoiber, Kimberley Supulver, Jason Van Beek, Tessa Van Beek, Robert Zimdar

Massachusetts Institute of Technology (MIT)

Katherine Louise French, Karl Iagnemma, Kristen Miller, Roger Summons

Max Planck Institute for Solar System Research

Fred Goesmann, Walter Goetz, Stubbe Hviid

Microtel

Micah Johnson, Matthew Lefavor, Eric Lyness

Mount Holyoke College

Elly Breves, M. Darby Dyar, Caleb Fassett

\section{NASA Ames}

David F. Blake, Thomas Bristow, David DesMarais, Laurence Edwards, Robert Haberle, Tori Hoehler, Jeff Hollingsworth, Melinda Kahre, Leslie Keely, Christopher McKay, Mary Beth Wilhelm

\section{NASA Goddard Space Flight Center (GSFC)}

Lora Bleacher, William Brinckerhoff, David Choi, Pamela Conrad, Jason P. Dworkin, Jennifer Eigenbrode, Melissa Floyd, Caroline Freissinet, James Garvin, Daniel Glavin, Daniel Harpold, Andrea Jones, Paul Mahaffy, David K. Martin, Amy McAdam, Alexander Pavlov, Eric Raaen, Michael D. Smith, Jennifer Stern, Florence Tan, Melissa Trainer

NASA Headquarters

Michael Meyer, Arik Posner, Mary Voytek

\section{NASA Jet Propulsion Laboratory (JPL)}

Robert C, Anderson, Andrew Aubrey, Luther W. Beegle, Alberto Behar, Diana Blaney, David Brinza, Fred Calef, Lance Christensen, Joy A. Crisp, Lauren DeFlores, Bethany Ehlmann, Jason Feldman, Sabrina Feldman, Gregory Flesch, Joel Hurowitz, Insoo Jun, Didier Keymeulen, Justin Maki, Michael Mischna, John Michael Morookian, Timothy Parker, Betina Pavri, Marcel Schoppers, Aaron Sengstacken, John J. Simmonds, Nicole Spanovich, Manuel de la Torre Juarez, Ashwin R. Vasavada, Christopher R. Webster, Albert Yen

NASA Johnson Space Center (JSC)

Paul Douglas Archer, Francis Cucinotta, John H. Jones, Douglas Ming, Richard V. Morris, Paul Niles, Elizabeth Rampe 
Nolan Engineering

Thomas Nolan

Oregon State University

Martin Fisk

Piezo Energy Technologies

Leon Radziemski

Planetary Science Institute

Bruce Barraclough, Steve Bender, Daniel Berman, Eldar Noe Dobrea, Robert Tokar, David Vaniman, Rebecca M. E. Williams, Aileen Yingst

Princeton University

Kevin Lewis

Rensselaer Polytechnic Institute (RPI)

Laurie Leshin

Retired

Timothy Cleghorn, Wesley Huntress, Gérard Manhès

Salish Kootenai College

Judy Hudgins, Timothy Olson, Noel Stewart

Search for Extraterrestrial Intelligence Institute (SETI I)

Philippe Sarrazin

Smithsonian Institution

John Grant, Edward Vicenzi, Sharon A. Wilson

Southwest Research Institute (SwRI)

Mark Bullock, Bent Ehresmann, Victoria Hamilton, Donald Hassler, Joseph Peterson, Scot Rafkin, Cary Zeitlin

Space Research Institute

Fedor Fedosov, Dmitry Golovin, Natalya Karpushkina, Alexander Kozyrev, Maxim Litvak, Alexey Malakhov, Igor Mitrofanov, Maxim Mokrousov, Sergey Nikiforov, Vasily Prokhorov, Anton Sanin, Vladislav Tretyakov, Alexey Varenikov, Andrey

Vostrukhin, Ruslan Kuzmin

Space Science Institute (SSI)

Benton Clark, Michael Wolff 
State University of New York (SUNY) Stony Brook

Scott McLennan

Swiss Space Office

Oliver Botta

TechSource

Darrell Drake

Texas A\&M

Keri Bean, Mark Lemmon

The Open University

Susanne P. Schwenzer

United States Geological Survey (USGS) Flagstaff

Ryan B. Anderson, Kenneth Herkenhoff, Ella Mae Lee, Robert Sucharski

Universidad de Alcalá

Miguel Ángel de Pablo Hernández, Juan José Blanco Ávalos, Miguel Ramos

Universities Space Research Association (USRA)

Myung-Hee Kim, Charles Malespin, Ianik Plante

University College London (UCL)

Jan-Peter Muller

University Nacional Autónoma de México (UNAM)

Rafael Navarro-González

University of Alabama

Ryan Ewing

University of Arizona

William Boynton, Robert Downs, Mike Fitzgibbon, Karl Harshman, Shaunna Morrison

University of California Berkeley

William Dietrich, Onno Kortmann, Marisa Palucis

University of California Davis

Dawn Y. Sumner, Amy Williams

University of California San Diego

Günter Lugmair

University of California San Francisco 
Michael A. Wilson

University of California Santa Cruz

David Rubin

University of Colorado Boulder

Bruce Jakosky

University of Copenhagen

Tonci Balic-Zunic, Jens Frydenvang, Jaqueline Kløvgaard Jensen, Kjartan Kinch, Asmus

Koefoed, Morten Bo Madsen, Susan Louise Svane Stipp

University of Guelph

Nick Boyd, John L. Campbell, Ralf Gellert, Glynis Perrett, Irina Pradler, Scott

VanBommel

University of Hawai'i at Manoa

Samantha Jacob, Tobias Owen, Scott Rowland

University of Helsinki

Evgeny Atlaskin, Hannu Savijärvi

University of Kiel

Eckart Boehm, Stephan Böttcher, Sönke Burmeister, Jingnan Guo, Jan Köhler, César

Martín García, Reinhold Mueller-Mellin, Robert Wimmer-Schweingruber

University of Leicester

John C. Bridges

University of Maryland

Timothy McConnochie

University of Maryland Baltimore County

Mehdi Benna, Heather Franz

University of Maryland College Park

Hannah Bower, Anna Brunner

University of Massachusetts

Hannah Blau, Thomas Boucher, Marco Carmosino

University of Michigan Ann Arbor

Sushil Atreya, Harvey Elliott, Douglas Halleaux, Nilton Rennó, Michael Wong

University of Minnesota 
Robert Pepin

University of New Brunswick

Beverley Elliott, John Spray, Lucy Thompson

University of New Mexico

Suzanne Gordon, Horton Newsom, Ann Ollila, Joshua Williams

University of Queensland

Paulo Vasconcelos

University of Saskatchewan

Jennifer Bentz

University of Southern California (USC)

Kenneth Nealson, Radu Popa

University of Tennessee Knoxville

Linda C. Kah, Jeffrey Moersch, Christopher Tate

University of Texas at Austin

Mackenzie Day, Gary Kocurek

University of Washington Seattle

Bernard Hallet, Ronald Sletten

University of Western Ontario

Raymond Francis, Emily McCullough

University of Winnipeg

Ed Cloutis

Utrecht University

Inge Loes ten Kate

Vernadsky Institute

Ruslan Kuzmin

Washington University in St. Louis (WUSTL)

Raymond Arvidson, Abigail Fraeman, Daniel Scholes, Susan Slavney, Thomas Stein, Jennifer Ward

Western University

Jeffrey Berger

York University 
Ming et al., Volatile and Organic Compositions of Sedimentary Rocks on Mars

John E. Moores 